\title{
Moderate strength (0.23-0.28 T) static magnetic fields (SMF) modulate signaling and differentiation in human embryonic cells Zhiyun Wang ${ }^{1}$, Anshu Sarje ${ }^{2}$, Pao-Lin Che ${ }^{1}$ and Kevin J Yarema*1
} Address: ${ }^{1}$ Department of Biomedical Engineering, The Johns Hopkins University, Baltimore, MD, USA and ${ }^{2}$ Department of Electrical and
Computer Engineering, University of Maryland, College Park, MD, USA

Email: Zhiyun Wang - zhiyun_wang@hotmail.com; Anshu Sarje - anshu.sarje@gmail.com; Pao-Lin Che - paulineche@jhu.edu; Kevin J Yarema* - kyarema1@jhu.edu

* Corresponding author

Published: 4 August 2009

BMC Genomics 2009, 10:356 doi:10.1 186/147/-2164-10-356
Received: 2 February 2009

Accepted: 4 August 2009

This article is available from: http://www.biomedcentral.com/I47I-2/64/10/356

(C) 2009 Wang et al; licensee BioMed Central Ltd.

This is an Open Access article distributed under the terms of the Creative Commons Attribution License (http://creativecommons.org/licenses/by/2.0), which permits unrestricted use, distribution, and reproduction in any medium, provided the original work is properly cited.

\begin{abstract}
Background: Compelling evidence exists that magnetic fields modulate living systems. To date, however, rigorous studies have focused on identifying the molecular-level biosensor (e.g., radical ion pairs or membranes) or on the behavior of whole animals leaving a gap in understanding how molecular effects are translated into tissue-wide and organism-level responses. This study begins to bridge this gulf by investigating static magnetic fields (SMF) through global mRNA profiling in human embryonic cells coupled with software analysis to identify the affected signaling pathways.

Results: Software analysis of gene expression in cells exposed to 0.23-0.28 T SMF showed that nine signaling networks responded to SMF; of these, detailed biochemical validation was performed for the network linked to the inflammatory cytokine IL-6. We found the short-term $(<24 \mathrm{~h})$ activation of IL-6 involved the coordinate up-regulation of toll-like receptor-4 (TLR4) with complementary changes to NEU3 and ST3GAL5 that reduced ganglioside GM3 in a manner that augmented the activation of TLR4 and IL-6. Loss of GM3 also provided a plausible mechanism for the attenuation of cellular responses to SMF that occurred over longer exposure periods. Finally, SMF-mediated responses were manifest at the cellular level as morphological changes and biochemical markers indicative of pre-oligodendrocyte differentiation.
\end{abstract}

Conclusion: This study provides a framework describing how magnetic exposure is transduced from a plausible molecular biosensor (lipid membranes) to cell-level responses that include differentiation toward neural lineages. In addition, SMF provided a stimulus that uncovered new relationships - that exist even in the absence of magnetic fields - between gangliosides, the timedependent regulation of IL-6 signaling by these glycosphingolipids, and the fate of embryonic cells.

\section{Background}

Life exists amid an electromagnetic background and it is therefore not surprising that biological systems are finely tuned to detect and react to static magnetic fields (SMF) of various strengths. In a well known example from nature, the migration of birds is guided by very low strength geo- magnetic fields [1-5]. In humans, there are intriguing reports - exemplified by an anecdotal Harvard study that showed severely depressed manic depressive patients experienced dramatic mood swings towards happiness during MRI [6] and pilot pain management clinical trials $[7,8]$ - that magnetic fields can benefit health. In more rig- 
orously controlled animal studies, beneficial effects on pain reduction [9], hypertension [10], wound healing [11], inflammation [12], and microvascular circulation [13] have been reported. To facilitate the translation of these early results to efficacious therapeutic modalities, a greater understanding of the underlying biological basis of magnetic exposure is required [13]. Accordingly, in this paper we take steps towards bridging the gap between the established biophysical effects of magnetic fields on subcellular macromolecular components and reported tissuelevel and whole organism responses by exploring whether SMF can function as a novel stimulus for signaling pathways at the cell level.

The premise that SMF can modulate signaling networks is based on reports that establish lipid bilayers as the most compelling molecular biosensors capable of responding to magnetic exposure. Specifically, moderate strength SMF can change biophysical properties of membranes that include hyperpolarization [14], redox potential [15], and fluidity [16] thereby altering flux through sodium $\left(\mathrm{Na}^{+}\right)$ [17] and calcium $\left(\mathrm{Ca}^{2+}\right)[13,16]$ channels. As a result, changes in cytosolic concentrations of the calcium ion which serves as a second messenger in several signaling pathways - occurs ubiquitously in cells exposed to SMF [18]. In addition to altering ion channel flux, biophysical changes to membranes may also affect lipid raft microdomains in ways that modulate downstream signaling; an example of this phenomenon is the impact of ethanol on lipid rafts and the concomitant changes to toll like receptor 4 (TLR4) activity [19]. In contrast to ethanol - which increases membrane domain fluidity - SMF exposure increases membrane rigidity, an effect that has been coupled to the promotion of differentiation in osteoblast-like cells [20].

In the first part this study, mRNA profiling of SMF-treated cells coupled with analysis of the microarray data by the Ingenuity Pathway Analysis software tool [21-23] verified that anticipated transcriptional changes - qualitatively consistent with the impact of altered $\mathrm{Ca}^{2+}$ flux or membrane domain fluidity on signaling pathways - did occur. Building on this finding, we conducted a detailed molecular and biochemical characterization of cellular elements linked to interleukin-6 (IL-6, which was identified to respond to SMF from the software analysis) in human embryonic cells. As a framework for the ensuing experiments described in this study, these connections are diagrammed in Figure 1; this figure shows both known connections between IL- 6 and other molecular players (e.g., $\mathrm{Ca}^{2+}$ and TLR4) as well previously unappreciated links (e.g., ganglioside involvement in IL-6 activation that acts even in the absence of SMF, offering a new controlling mechanism for IL-6). This study concludes by showing that SMF leads towards oligodendrocyte differentiation in human embryonic cells by preferentially stimulating preoligodendrocyte markers over the astrocyte markers usually associated with IL- 6 exposure. Together, these results establish SMF as an intriguing means to ultimately (and non-invasively) stimulate cells in an endogenous niche.

\section{Results and discussion \\ Transcriptional profiling and Ingenuity Pathway Software analysis}

To gain evidence for the hypothesis that SMF exposure activates or otherwise modulates signaling networks, human embryoid body derived (hEBD) cells [24] were exposed to $0.23-0.28$ T fields and mRNA microarray profiling was used to determine changes to global patterns of gene expression. In the first tests, 15 min SMF exposure (followed by one day recovery) was tested based on reports that gene expression responded to magnetic exposure this quickly [25]. In our evaluation, however, only two genes were up- and down-regulated with a statistical probability > 95\% (Table 1) and none met the common benchmark of a 2- (or even 1.75-) fold change. Nonetheless, the reproducibility over multiple probes for the same gene indicated that these modest changes were real and provided impetus to investigate longer term exposure.

Indeed, after one day ( $24 \mathrm{~h}$ ) of SMF treatment, 379 genes were up-regulated and 549 were down-regulated with statistical significance (Figure 2A); even greater changes were seen after 4 or 5 days of exposure. The magnitude of the change for most genes, however, was modest (Figure 2B) with only 7 showing up-regulation $\geq 2$-fold (Figure 2C) and 20 showing a similar degree of down-regulation (Figure 2D). After 5 days of continuous SMF exposure, the number of genes up-regulated by $\geq 2$-fold increased to 85 (Figure 2C) while 94 were down-regulated to a similar extent. Interestingly, in an experiment where the cells were allowed to recover for one day under normal culture conditions after prolonged SMF exposure, the number of genes that remained up-regulated by $\geq 2$-fold fell by almost half (from 85 to 47 , Figure 2C) whereas the number of down-regulated genes increased by 35 (Figure 2D).

The microarray results were consistent with the activation of signal transduction pathways over the short term (i.e., in less than one day) leading to an amplified set of genetic changes over the next several days. A simple inspection of transcriptional changes (for example, the top 5 up- and down-regulated genes under each exposure condition listed in Tables 2, 3, and 4) did not lead to any obvious insights into the over-riding effects of SMF however. Therefore, to flesh out this hypothesis, the Ingenuity Pathway Analysis software tool $[21,26]$ was used to analyze the microarray data resulting in the identification of nine networks that responded to SMF exposure in hEDB LVED 


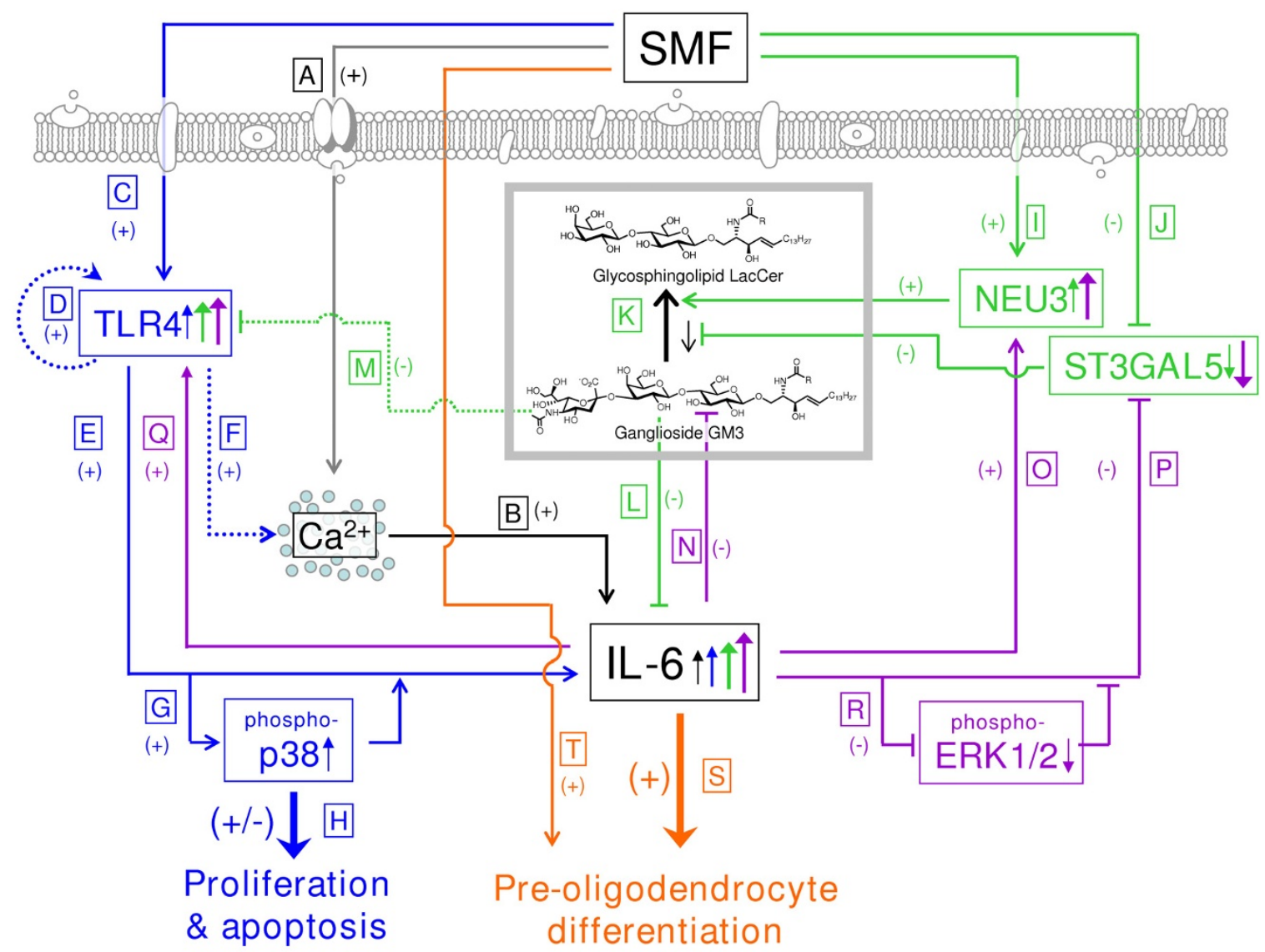

Figure I

Overview of crosstalk between SMF and IL-6. Connections between SMF and IL-6 are shown in black, TLR4 in blue, gangliosides in green, feed-forward regulation of IL-6 on itself in purple, and whole cell responses (e.g., differentiation) in orange. Connections supported by data collected in this work are shown by solid lines (and the location of this data in subsequent figures is provided); dotted lines show connections based on the literature, as referenced. (A) SMF exposure modulates calcium flux (Fig. 3C and Fig. I IA). (B) Early increases in IL-6 mRNA levels (within $2 \mathrm{~h}$, Fig. 3A) occur followed by increased levels of secreted IL-6 (within 7 h, Fig. 3B). (C) Likewise, SMF activates TLR4 (Fig. 3D), resulting in (D) feed-forward self-stimulation [4I]. (E) In turn, TLR4 leads to IL-6 activation either through (F) a reported $\mathrm{Ca}^{2+}$-dependent route [39] or (G) through changes to $\mathrm{p} 38$ phosphorylation (Fig. 4A) that $(\mathbf{H})$ transiently hinder proliferation in hEBD LVEC cells (Fig. 4B) without leading to apoptosis (Fig. 4C\& D). SMF also has early-acting effects on NEU3 (I) and ST3GAL5 (J) mRNA levels (Fig. 8F) with (K) a concomitant decrease in ganglioside levels (Fig. 8B\&C). (L) In the absence of SMF, exogenously-added ganglioside GM3 suppresses IL-6 production (Fig. 6A) and (M) TLR4 [38]. (N) IL-6 reduces ganglioside levels (Fig. 6B) through changes to (O) NEU3 and (P) ST3GAL5 mRNA levels (Fig. 7D) that (R) involve ERKI/2 phosphorylation (Fig. 7B\&C). 'Downstream' responses to the combined administration of (S) IL-6 and (T) SMF include reproducible changes in cell morphology (Fig. 9E) and biochemical markers consistent with pre-oligodendrocyte differentiation (Fig. 10).

cells (Table 5; data analysis is shown for cells subject to five days of continuous SMF exposure and the annotated networks are provided in Additional file 1). Several of these pathways reflected known biological responses to magnetic exposure. For example, changes to intracellular $\mathrm{Ca}^{2+}$ pools observed in cell lines exposed to SMF $[18,27]$ were consistent with interleukin-6 (IL-6) centered signaling responses (ID\#2, Table 5) mediated through the ability of this cytokine to be modulated by $\mathrm{Ca}^{2+}$ flux [28].
Similarly, Wnt responses (ID\#6, Table 5) can be activated by a non-canonical $\mathrm{Ca}^{2+}$ dependent mechanism [29]. Moving above the cell level, two networks were identified (ID\#3 and ID\#5) that related to cardiovascular development and hematological function, respectively, and thus dovetail with a recent report by Morris and Skalak where SMF exposure of $0.06-0.14 \mathrm{~T}$ for a comparable time period (seven days) facilitated micro-vessel regeneration after surgical intervention [13]. Likewise, Strieth and 
Table I: Microarray profiling of mRNA levels in hEBD cells exposed to SMF for $15 \mathrm{~min}$.

\begin{tabular}{|c|c|c|c|c|c|}
\hline \multirow[t]{2}{*}{ Affy Probeset ID } & \multirow[t]{2}{*}{ Gene Title } & \multirow[t]{2}{*}{ Gene Symbol } & \multirow{2}{*}{$\begin{array}{c}\text { Ratio } \\
\text { (+ or -) fold-regulation }\end{array}$} & \multicolumn{2}{|c|}{ Average Signals } \\
\hline & & & & Control & Experimental \\
\hline \multicolumn{6}{|l|}{ Up-regulated genes: } \\
\hline 209189_at & $\begin{array}{l}\text { v-fos FBJ murine osteosarcoma viral oncogene } \\
\text { homolog }\end{array}$ & FOS & $(+) 1.59$ & 105.4 & 168.0 \\
\hline 1562836_at & DEAD (Asp-Glu-Ala-Asp) box polypeptide 6 & DDX6 & $(+) 1.59$ & 226.5 & 359.8 \\
\hline 205195_at & adaptor-related protein complex I, sigma I subunit & APISI & $(+) 1.48$ & 212.1 & 314.4 \\
\hline 219730_at & $\begin{array}{l}\text { mediator of RNA polymerase II transcription, } \\
\text { subunit I } 8 \text { homolog (yeast) }\end{array}$ & MEDI 8 & $(+) 1.47$ & 20.3 & 29.7 \\
\hline 209189_at & $\begin{array}{l}\text { v-fos FBJ murine osteosarcoma viral oncogene } \\
\text { homolog }\end{array}$ & FOS & $(+) 1.59$ & 105.4 & 168.0 \\
\hline \multicolumn{6}{|c|}{ Down-regulated genes: } \\
\hline AFFX-BioB-3_at & Biotin synthase///biotin synthesis, sulfur insertion & bioB & (-) 1.70 & 422.5 & 275.5 \\
\hline AFFX-r2-Ec-bioC-5_at & $\begin{array}{l}\text { Biotin synthesis protein bioC///biotin biosynthesis; } \\
\text { reaction prior to pimeloyl CoA }\end{array}$ & bioc & (-) 1.62 & 1185.5 & 732.7 \\
\hline AFFX-BioDn-5_at & dethiobiotin synthetase & bioD & $(-) 1.52$ & 1181.8 & 734.2 \\
\hline
\end{tabular}

coauthors have reported that SMF affects the vascular and blood flow [30] and Okano and coworkers have investigated the modulation of blood vessels by magnetic fields [10,31-33].

\section{SMF increased IL-6 mRNA levels and protein secretion at early time points}

Even though the software analysis of the microarray data was consistent with a mechanism wherein SMF acted as a stimulus for signaling pathways, limitations of this methodology precluded any firm conclusions. Signaling pathway responses, for example, are typically measured over time intervals of minutes to hours and require evaluation with closely-spaced time points not practical by microarray profiling over several days. Therefore, to verify that the transcriptional changes we observed represented legitimate responses to SMF, we selected IL-6 for conventional biochemical characterization. Of the nine networks identified by microarray profiling, the selection of IL- 6 for additional scrutiny was based on several factors. First, a recent report linked 0.4 T SMF exposure to increased IL-6 production in fibroblasts [34] and plausible membranebased modes of activation IL-6 (e.g., through $\mathrm{Ca}^{2+}$ or TLR4) exist. Furthermore, reports that SMF can promote differentiation [20] - coupled with the propensity of the hEBD LVEC line used in this study to display neural markers [24] together with reports that IL-6 promotes astrocytogenesis [35] - offered the possibility that cell-level responses (e.g., differentiation of the hEBD cells to astrocytes) could be observed in these experiments.

Biochemical validation began by quantitative real-time polymerase chain reaction (qRT-PCR) analysis of IL-6 mRNA levels over the first $24 \mathrm{~h}$ of SMF exposure, a time frame selected based on the numerous changes seen in the microarray data after one day (Figure 2) and literature reports of biphasic IL-6 activation during this time period
[36]. In these experiments, IL-6 mRNA levels increased two hours into SMF exposure and remained elevated compared to untreated control cells at 4, 7 and 24 h (Figure 3A). IL-6 secretion into the culture medium followed slower kinetics, first showing a measurable increase at $7 \mathrm{~h}$ after which SMF-treated cells out-produced control cells up to $96 \mathrm{~h}$ (Figure 3B). The SMF-exposed cells experienced the largest relative increase compared to untreated controls at $48 \mathrm{~h}$, followed by a decline to slightly less than control levels at the end of the six day monitoring period.

\section{TLR4 was activated by SMF in tandem with IL-6}

Upon verifying that IL- 6 was activated by SMF at both the mRNA and protein levels, we sought more detailed insight into this response. As indicated in Figure 1A \&1B (for perspective, Figure 1 summarizes the connections between SMF, IL- 6 and other pathways elements and cellular outcomes described in this report), IL- 6 activation was consistent with the known ability of magnetic fields to alter calcium ion channel flux and reports of $\mathrm{Ca}^{2+}$ dependent up-regulation of IL- 6 (the impact of SMF on calcium flux was experimentally verified for currentlyused hEBD LVEC cells, Figure 3C). In addition, connections IL-6 shares with TLR4 [37-39], combined with the dependence of the signaling activity of Toll-like receptors on their lateral diffusion within membrane microdomains $[19,40]$, suggested a parallel route through which SMF could influence IL- 6 . Specifically, a sequence of events can be postulated where SMF changes membrane fluidity thereby modulating TLR4 (Figure 1C) and downstream IL-6 responses (Figure 1E) through a $\mathrm{Ca}^{2+}$-dependent mechanism (Figure 1F) or through TLR4-mediated p38 phosphorylation (Figure 1G).

Experimentally, because TLR4 transcription is strictly auto-regulated in a stimulus-dependent manner $([38,41]$ and Figure 1D), qRT-PCR can be used to monitor its acti- 
(A)

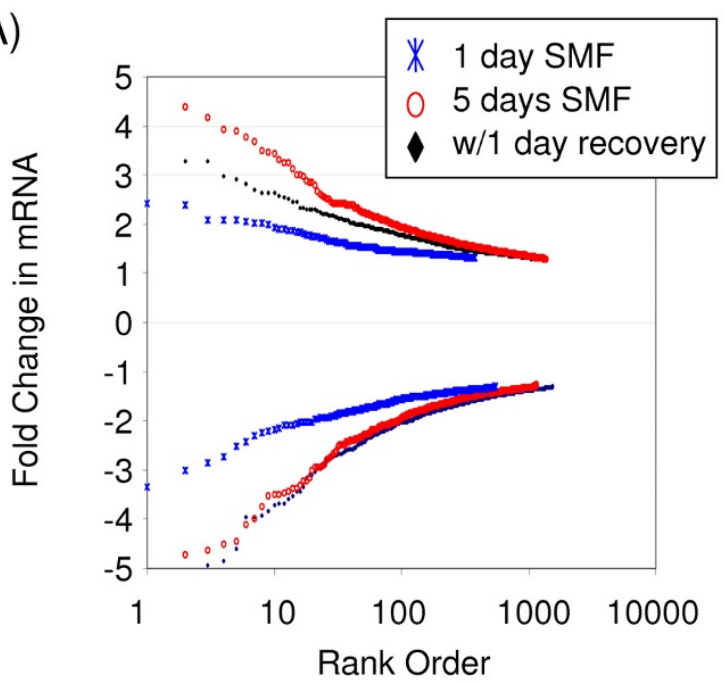

(C) Genes up-regulated by $>2$-fold

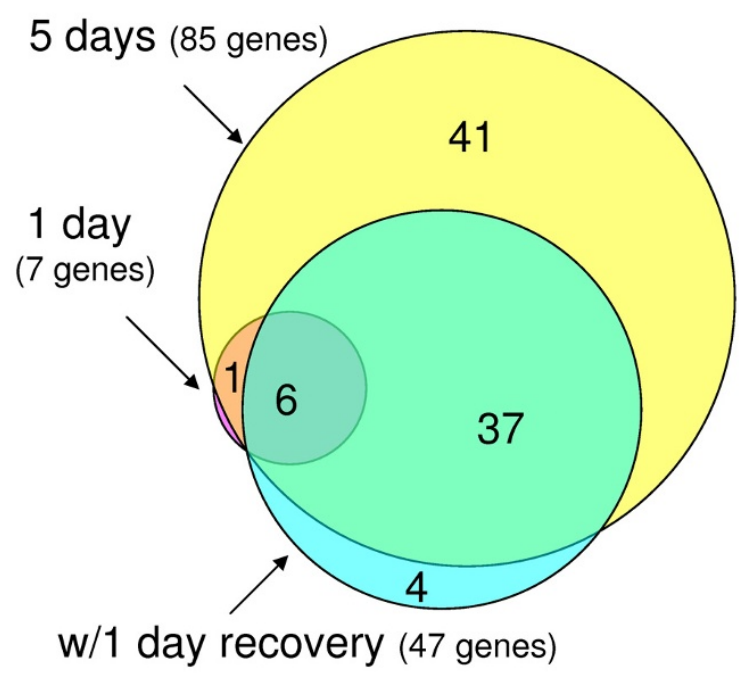

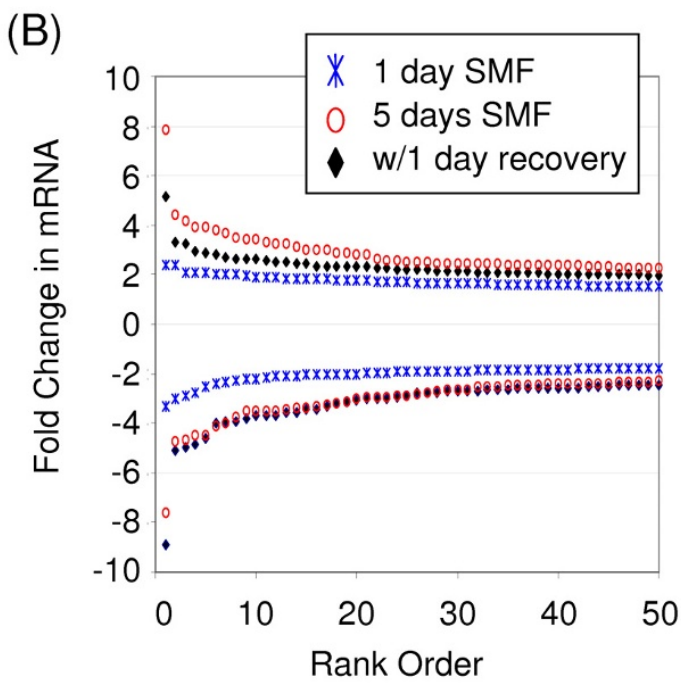

(D) Genes down-regulated by $>$ 2-fold 5 days (94 genes)

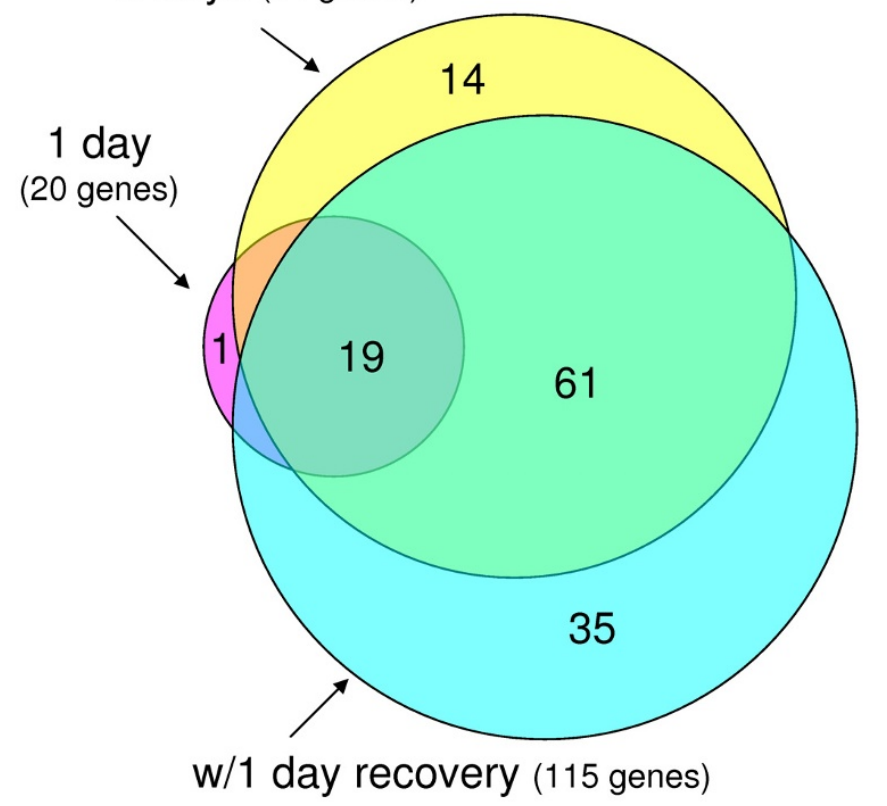

\section{Figure 2}

mRNA profiling of SMF-treated hEBD cells. (A) The magnitude and number of genes that showed statistically significant changes in mRNA levels after SMF exposure compared to untreated control cells are given (four data points, representing genes with $\geq 5$-fold changes in mRNA levels are not indicated in (A) but are shown in the expanded view of the 50 highest upand down-regulated genes provided in (B); the "missing" genes are listed in Tables 2-4). Venn diagrams depicting the number of genes up- or down-regulated by $\geq 2$-fold compared to cells continuously incubated under normal culture conditions are shown in Panels $\mathbf{C}$ and $\mathbf{D}$, respectively. Note that the "I day SMF" designation refers to the Group $\mathbf{2}$ treatment conditions described in the Methods section, (the greatest up- and down-regulated genes are listed in Table 2); " 5 days SMF" refers to Group 3 cells (Table 3); and "w/I day recovery" refers to Group 4 cells (Table 4); in all cases comparison is made to Group I control cells that were not exposed to SMF. 
Table 2: Gene expression for hEBD LVEC cells exposed to SMF for one day (i.e., "Group 2") compared to control cells incubated without SMF exposure (Group I).

\begin{tabular}{|c|c|c|c|c|c|}
\hline \multirow[t]{2}{*}{ Affymetrix Probeset ID } & \multirow[t]{2}{*}{ Gene Designation } & \multirow[t]{2}{*}{ Gene Symbol } & \multirow{2}{*}{$\begin{array}{c}\text { Ratio } \\
(+ \text { or -) fold-regulation }\end{array}$} & \multicolumn{2}{|c|}{ Average Signals } \\
\hline & & & & Control & Experimental \\
\hline \multicolumn{6}{|l|}{ Up-regulated genes: } \\
\hline 1554452_a_at & hypoxia-inducible protein 2 & HIG2 & $(+) 2.41$ & 328.9 & 792.0 \\
\hline 230746_s_at & Stanniocalcin I & STCI & $(+) 2.40$ & 1035.7 & 2483.9 \\
\hline 218149_s_at & zinc finger protein 395 & ZNF395 & $(+) 2.08$ & 349.4 & 725.9 \\
\hline 218507_at & hypoxia-inducible protein 2 & HIG2 & $(+) 2.08$ & 391.7 & 813.4 \\
\hline 223216_x_at & zinc finger protein $395 / / / F-b o x$ protein 16 & ZNF395///FBXOI6 & $(+) 2.05$ & 241.7 & 495.4 \\
\hline \multicolumn{6}{|l|}{ Down-regulated genes: } \\
\hline 217967_s_at & chromosome I open reading frame 24 & Clorf24 & $(-) 3.34$ & 848.5 & 254.0 \\
\hline 205569_at & lysosomal-associated membrane protein 3 & LAMP3 & (-) 3.01 & 186.3 & 61.9 \\
\hline 229778_at & Hypothetical protein & MGCI0946 & (-) 2.74 & 159.6 & 58.3 \\
\hline 209774_x_at & chemokine (C-X-C motif) ligand 2 & CXCL2 & $(-) 2.52$ & 611.4 & 242.4 \\
\hline 220892_s_at & phosphoserine aminotransferase I & PSATI & $(-) 2.42$ & 2701.91 & 1116.08 \\
\hline 205207_at & interleukin 6 (interferon, beta 2) & IL6 & $(-) 1.93$ & & 266.3 \\
\hline
\end{tabular}

vation. By monitoring this endpoint, we found that TLR4 transcript levels increased during the first several hours of SMF exposure (Figure 3D). Interestingly, self-activation of TLR4 can lead to either the down-regulation of its mRNA (as seen in rat glial [38] or murine macrophages [42]) or to up-regulation (as seen in murine lung [37] or human monocytes and polymorphonuclear leukocytes [43]); the current up-regulation of TLR4 mRNA observed in SMFtreated embryonic cells is consistent with results obtained in other types of human cells upon activation of TLRs.

\section{SMF activation of TLR4 impinges upon MAPK pathways}

The activation of IL-6 in cells exposed to SMF was consistent with signal transduction through the upstream involvement of TLR4 (Figure 1E\&1G). To gain biochemical evidence for this connection, we analyzed the phos- phorylation of p38, which lies in the pathway that connects TLR4 with IL-6, and found the predicted increase in phosphorylated p38 in SMF treated cells (Figure 4A). This result, in addition to establishing a connection between IL-6 and SMF through TLR4, provided evidence that SMF impinges on MAPK signaling (p38 plays a central role in mediating MAPK responses) prompting us to evaluate changes to proliferation and apoptosis. In these experiments a significant reduction in proliferation was seen for hEBD LVEC cells after three days of SMF exposure; this effect lessened by the sixth day and was lost by the ninth day (Figure 4B). Qualitatively, this short term change in proliferation was consistent with studies where SMF transiently altered proliferation [44]. Annexin/propidium iodide staining assays showed that reduced proliferation during early phases of SMF exposure was not a

Table 3: Gene expression for hEBD LVEC cells exposed to SMF for five days (i.e., Group 3) compared to control cells incubated without SMF exposure (Group I).

\begin{tabular}{|c|c|c|c|c|c|}
\hline \multirow[t]{2}{*}{ Affymetrix Probeset ID } & \multirow[t]{2}{*}{ Gene Designation } & \multirow[t]{2}{*}{ Gene Symbol } & \multirow{2}{*}{$\begin{array}{c}\text { Ratio } \\
\text { (+ or -) fold-regulation }\end{array}$} & \multicolumn{2}{|c|}{ Average Signals } \\
\hline & & & & Control & Experimental \\
\hline \multicolumn{6}{|l|}{ Up-regulated genes: } \\
\hline 242517_at & G protein-coupled receptor 54 & GPR54 & $(+) 7.84$ & 60.1 & 470.7 \\
\hline I554452_a_at & $\begin{array}{l}\text { hypoxia-i hypoxia-inducible protein } 2 \text { nducible } \\
\text { protein } 2\end{array}$ & HIG2 & $(+) 4.40$ & 328.9 & 1446.4 \\
\hline 205493_s_at & dihydropyrimidinase-like 4 & DPYSL4 & $(+) 4.17$ & 184.1 & 767.3 \\
\hline 226682_at & hypothetical protein & LOC283666 & $(+) 3.91$ & 391.7 & 1530.5 \\
\hline 22643I_at & $\begin{array}{l}\text { amyotrophic lateral sclerosis } 2 \text { (juvenile) } \\
\text { chromosome region, candidate } 13\end{array}$ & ALS2CRI3 & $(+) 3.79$ & 80.9 & 306.4 \\
\hline 232068_s_at & toll-like receptor 4 & TLR4 & $(+) 1.58$ & 195.4 & 309.5 \\
\hline \multicolumn{6}{|l|}{ Down-regulated genes: } \\
\hline 217967_s_at & chromosome I open reading frame 24 & Clorf24 & (-) 7.60 & 848.5 & 111.7 \\
\hline 220892_s_at & phosphoserine aminotransferase I & PSATI & (-) 4.72 & 2701.9 & 572.5 \\
\hline 205047_s_at & asparagine synthetase & ASNS & (-) 4.64 & 2327.5 & 501.5 \\
\hline 210587_at & inhibin, beta $E$ & INHBE & (-) 4.12 & 176.6 & 42.8 \\
\hline 204475_at & $\begin{array}{l}\text { matrix metallopeptidase I } \\
\text { (interstitial collagenase) }\end{array}$ & MMPI & (-) 3.98 & 112.8 & 28.3 \\
\hline 205207_at & interleukin 6 (interferon, beta 2) & IL-6 & (-) 3.23 & 513.2 & 158.9 \\
\hline
\end{tabular}


Table 4: Gene expression for hEBD LVEC cells exposed to SMF for four days followed by one day of recovery (i.e., Group 4) compared to cells incubated without SMF exposure (Group I).

\begin{tabular}{|c|c|c|c|c|c|}
\hline \multirow[t]{2}{*}{ Affymetrix Probeset ID } & \multirow[t]{2}{*}{ Gene Designation } & \multirow[t]{2}{*}{ Gene Symbol } & \multirow{2}{*}{$\begin{array}{c}\text { Ratio } \\
(+ \text { or }-) \text { fold-regulation }\end{array}$} & \multicolumn{2}{|c|}{ Average Signals } \\
\hline & & & & Control & Experimental \\
\hline \multicolumn{6}{|l|}{ Up-regulated genes: } \\
\hline 242517_at & G protein-coupled receptor 54 & GPR54 & $(+) 5.16$ & 60.1 & 310.0 \\
\hline 205200_at & C-type lectin domain family 3 , member B & CLEC3B & $(+) 3.28$ & $\mid 11.1$ & 364.7 \\
\hline 205493_s_at & dihydropyrimidinase-like 4 & DPYSL4 & $(+) 3.27$ & 184.1 & 601.7 \\
\hline 218149_s_at & zinc finger protein 395 & ZNF395 & $(+) 2.96$ & 409.4 & 1212.0 \\
\hline 1554452_a_at & hypoxia-inducible protein 2 & HIG2 & $(+) 2.90$ & 328.9 & 955.0 \\
\hline 232068_s_at & toll-like receptor 4 & TLR4 & $(+) 1.36$ & 195.4 & 266.5 \\
\hline \multicolumn{6}{|l|}{ Down-regulated genes: } \\
\hline 217967_s_at & chromosome I open reading frame 24 & Clorf24 & (-) 8.90 & 848.5 & 95.3 \\
\hline 205047_s_at & asparagine synthetase & ASNS & (-) 4.95 & 2327.5 & 470.0 \\
\hline 223062_s_at & phosphoserine aminotransferase I & PSATI & (-) 4.84 & 3784.5 & 781.5 \\
\hline 210587_at & inhibin, beta $\mathrm{E}$ & INHBE & (-) 3.96 & 176.6 & 44.6 \\
\hline 229778_at & Hypothetical protein & MGCI0946 & (-) 3.95 & 159.6 & 40.5 \\
\hline 205207_at & interleukin 6 (interferon, beta 2) & IL6 & (-) 3.16 & 513.2 & 162.4 \\
\hline
\end{tabular}

consequence of increased apoptosis (Figure 4C\&4D) in agreement with reports that SMF, if anything, is protective against apoptosis $[18,45]$. Having ruled out that the SMF treated cells were dying, a plausible explanation for the reduced proliferation was that the cells were undergoing differentiation with a concomitant decrease in their growth rate; this possibility was supported by data presented later in this report.

\section{SMF responses are cell line dependent}

As a brief diversion from the main thrust of this study, which was to connect SMF with cellular responses associated with IL-6 in human embryonic cells, we wish to emphasize that the impact of SMF on other common laboratory cells such as the Jurkat, HeLa, and HEK AD293 lines was surveyed and "obvious" effects such as pronounced changes in proliferation (as seen in Figure 4B for the hEBD LVEC line) or altered morphology (as shown later in this report) were not observed. For example, representative data is shown for the HEK AD293 line in Figure 5 where control and SMF-exposed cells had identical growth rates when measured by either the MTT assay (Panel A) or through cell counting (Panel B). The clear-cut differences seen between the embryonic hEBD LVEC line and cancer lines were not surprising based on reports that even closely-matched cell lines respond uniquely to SMF [46]; instead these findings support the hypothesis that changes to $\mathrm{Ca}^{2+}$ flux (as shown in Figure 3C) - a parameter that is highly cell line dependent [18] - contributes to the cellular responses we observed in the cells exposed to SMF.

\section{Connections between gangliosides and IL-6 exist in hEBD LVEC cells}

To gain insight into whether regulatory networks beyond TLR4 or calcium flux contributed to the up-regulation of IL-6 in SMF treated cells, we next focused on gangliosides [38,47]. Gangliosides are sialic acid-bearing glycosphingolipids (GSLs) that are integral components of lipid rafts and caveolae of the type surrounding TLR4 that not only organize these microdomains but also regulate the signaling functions of embedded proteins (as discussed in more

Table 5: Signaling networks identified to respond to SMF exposure through data analysis with the Ingenuity Pathway Analysis software tool.'

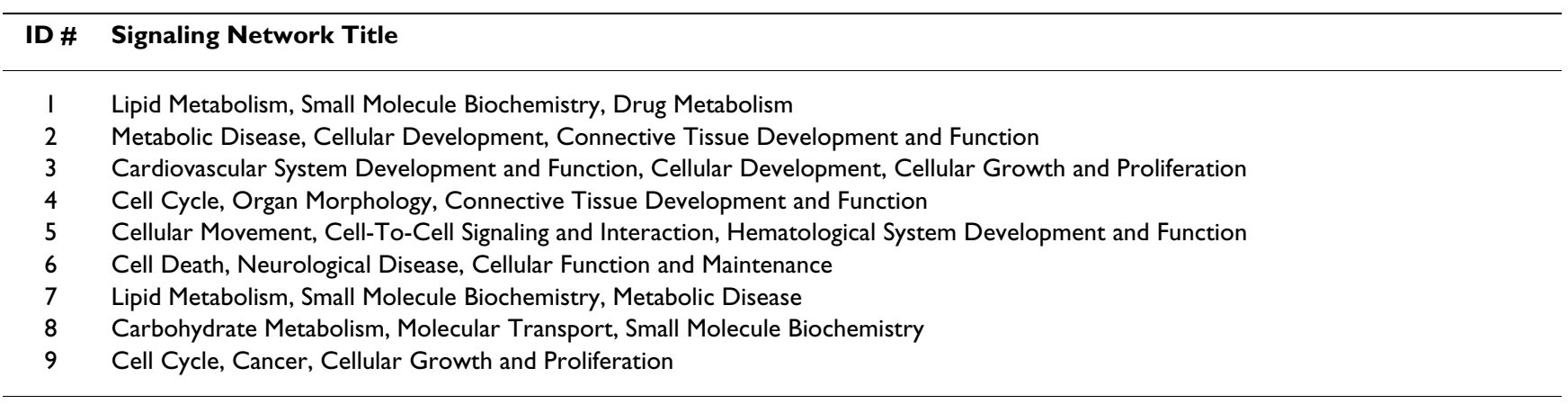

\footnotetext{
I Annotated network diagrams are provided in Additional file I.
} 
(A)

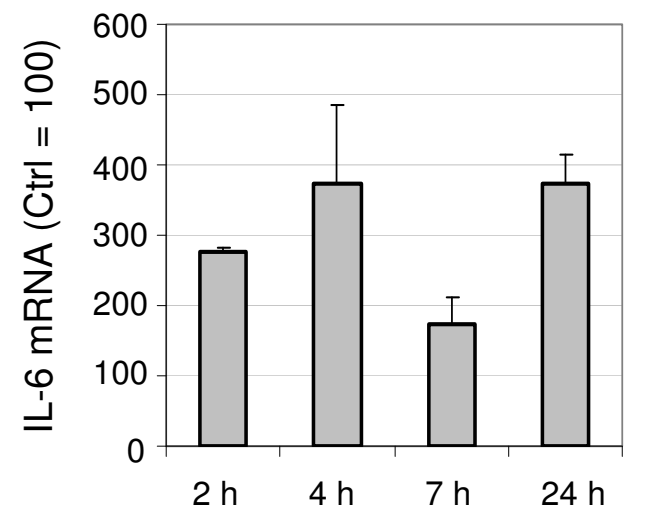

Duration of SMF Exposure

(C)

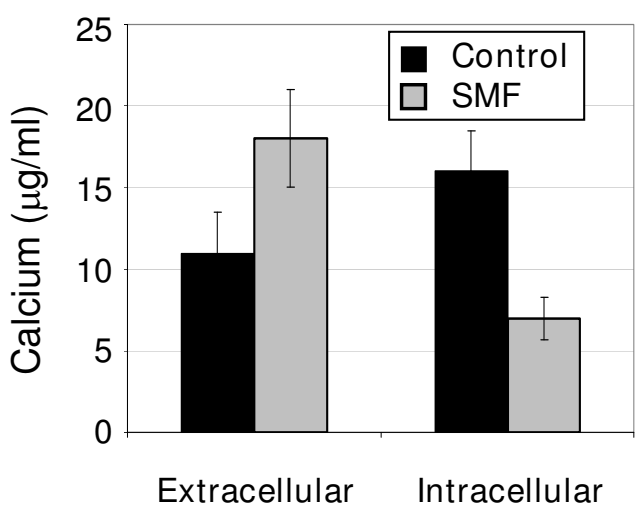

(B)

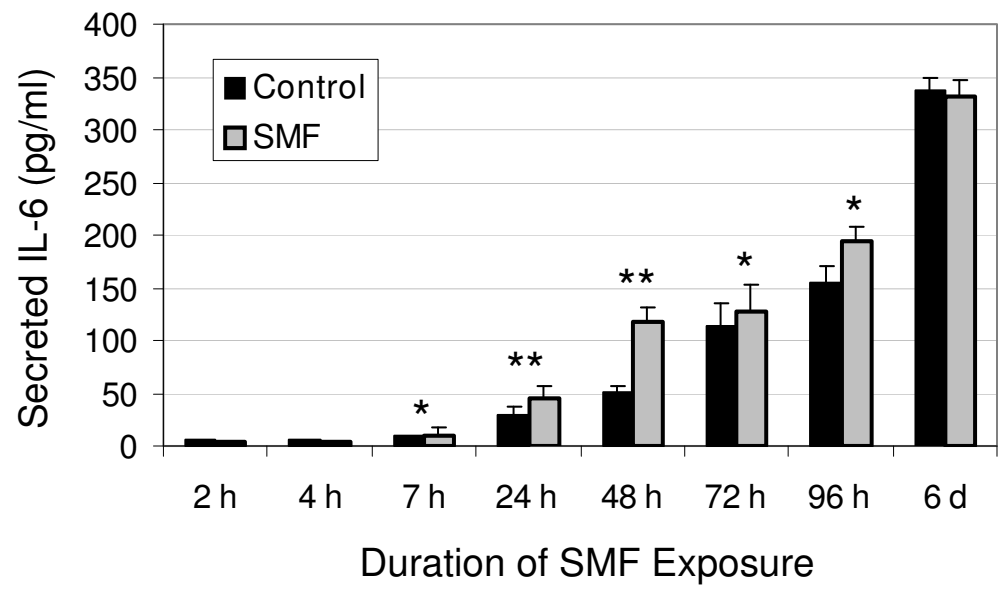

(D)

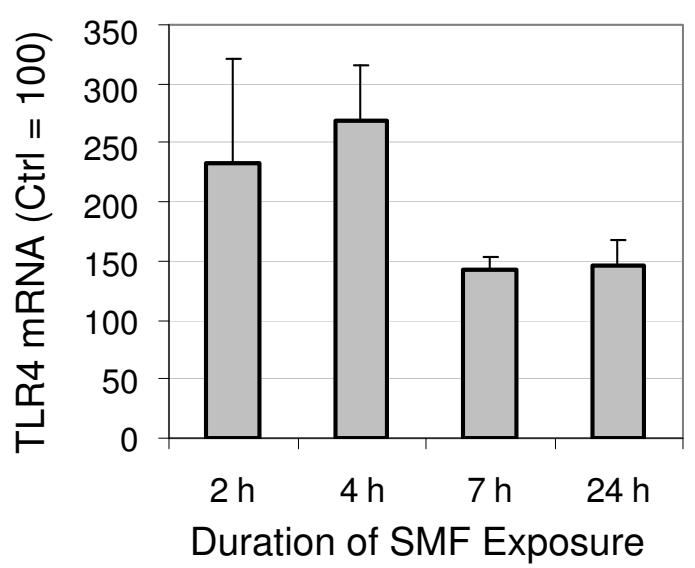

Figure 3

Response of interleukin-6 (IL-6) to SMF exposure and putative activating mechanisms in hEBD LVEC cells. (A) Levels of IL-6 mRNA were determined by qRT-PCR during the first $24 \mathrm{~h}$ of SMF exposure. (B) IL-6 concentrations in the culture medium of SMF-exposed and control cells were determined by ELISA at the indicated times. (C) Levels of extracellular and intracellular calcium after four hours of SMF exposure show the expected reciprocal relationship (a time course for extracellular calcium is shown in Figure IIA). (D) Levels of TLR4 mRNA were determined by qRT-PCR during the first $24 \mathrm{~h}$ of SMF exposure. In all cases the data shown represents three or more independent experiments (denoted as $n \geq 3$ in subsequent figure legends) and error bars represent standard (SD); in Panels $\mathbf{A}, \mathbf{C}$, and $\mathbf{D}, p<0.05$ for all data points shown that compare SMF-treated and control cells; in Panel $\mathbf{B}$, "*" indicates $p<0.05$ and "**" indicates $p<0.01$ (in this figure, and throughout this study, statistical significance was determined by the Student t-test and differences were considered to be significant when $p<$ 0.05 (or $p<0.0$ I when specifically indicated)).

detail in review articles $[48,49])$. Consequently, TLR4 [38] and IL-6 [47] can be influenced by the equilibrium between the 'inert' (in this context) GSL lactosylceramide (LacCer) and the suppressive ganglioside GM3 (Figure $1 \mathrm{~K})$.

Before beginning experiments to probe the impact of SMF exposure on gangliosides, the relationship between GM3 (and its disialylated derivative GD3) and IL-6 was first investigated to establish a baseline for the hEBD LVEC line (before the current study, there was negligible literature precedent for a connection between GSL and IL-6 in human embryonic cells). A long-lasting and substantial (e.g., > 95\% at $4 \mathrm{~d}$ ) reduction in IL-6 mRNA was observed in cells incubated with exogenously-added GM3 or GD3 (Figure 6A). Crosstalk between gangliosides and IL-6 also held in the reverse direction as demonstrated by a dose dependent decrease in GM3 in cells incubated with exog- 
(A)

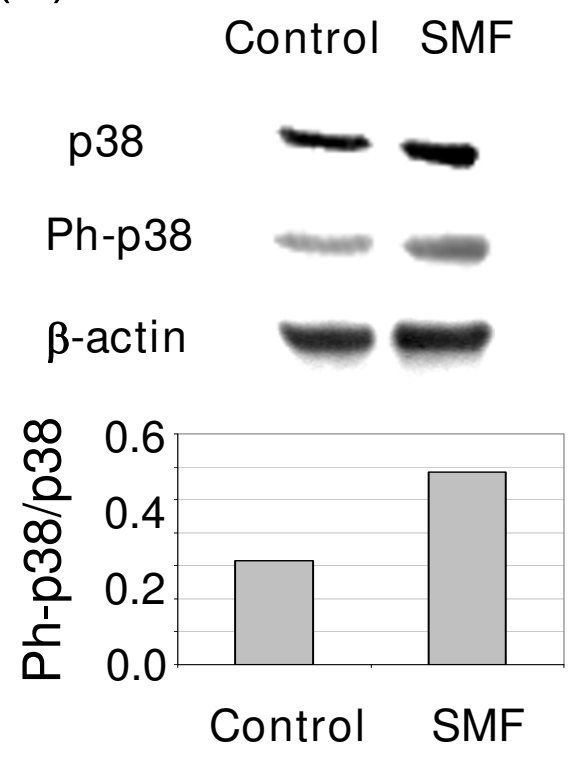

(C) SMF

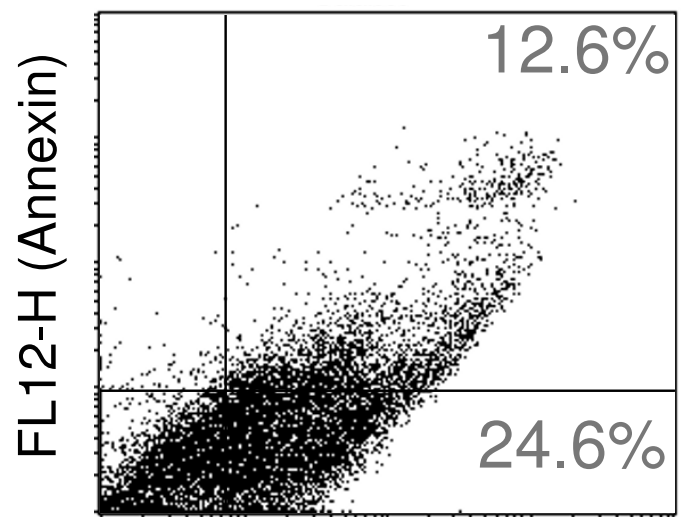

FL1-H (PI)

(B)

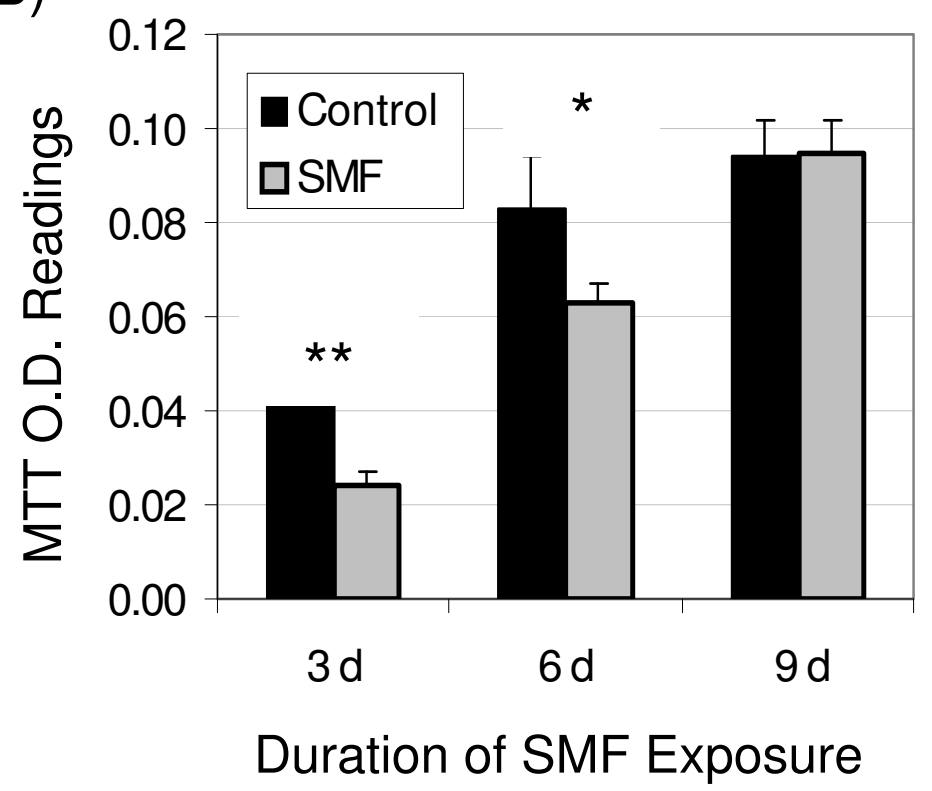

(D) Control

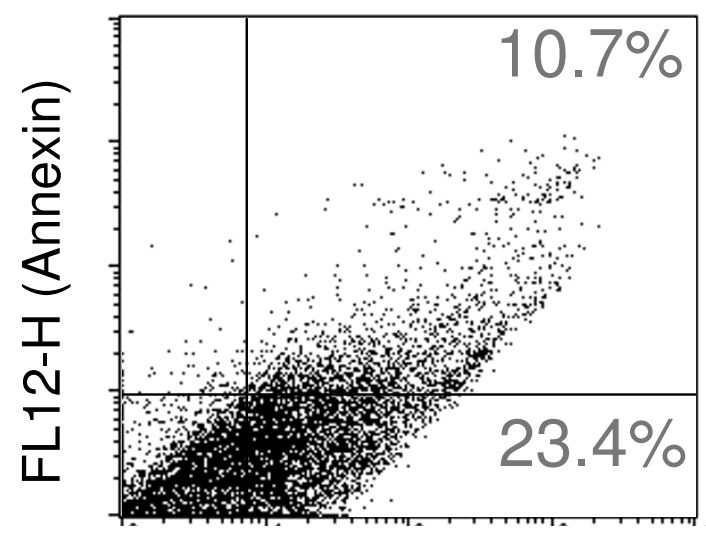

FL1-H (PI)

\section{Figure 4}

MAPK-related responses to SMF in hEBD LVEC cells. (A) An increase in p38 phosphorylation occurred in the SMFtreated cells (representative results from one of three experiments is shown for 30 min of SMF exposure; a normalized ratio of phosphorylated p38 (Ph-p38) to p38 is provided in the bar graph after quantification of the western blots by densitometry). (B) Proliferation of SMF-exposed cells decreased over the first 6 days of SMF exposure but not at nine days (error bars represent SD for $n \geq 3$ independent experiments and "*" indicates $p<0.05$ and "**" indicates $p<0.01$ ). No change in the number of apoptotic cells was detected after SMF exposure when evaluated by the Annexin V/propidium iodide assay (Panel C; representative data from one of three experiments is shown) compared to control cells (Panel D). 


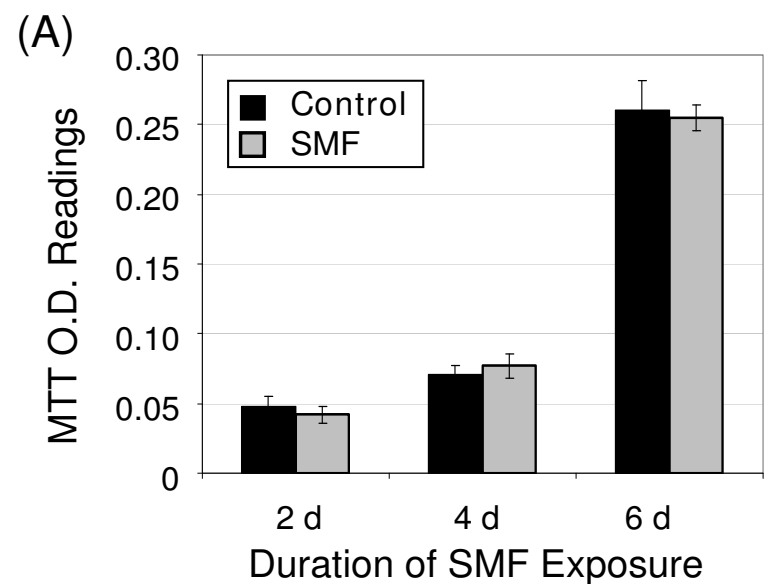

(B)

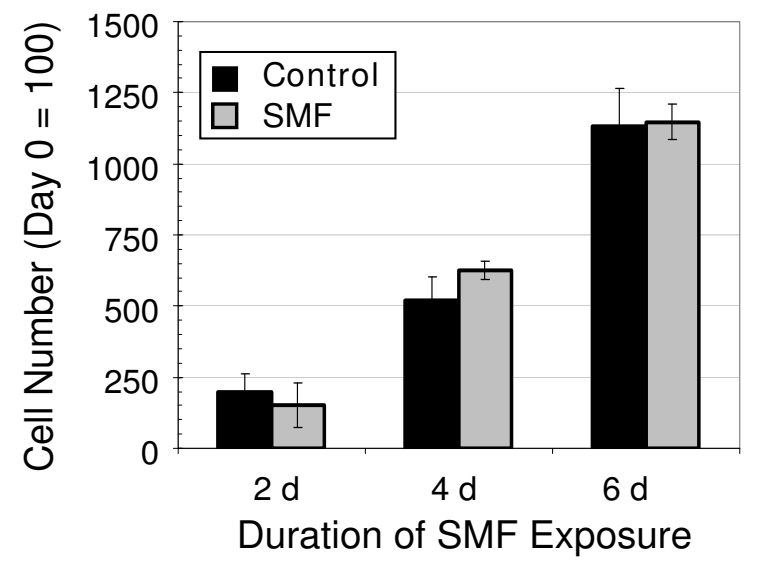

Figure 5

Proliferation is not altered by SMF in HEK AD293 cells. The cell line dependence of SMF effects is illustrated by the lack of a response in SMF-treated HEK AD293 cells when proliferation was measured by the MTT assay (Panel A) or by cell counts (Panel B). Error bars represent SD for $n \geq 3$ independent experiments and in all cases $p>0.05$.

enously-added IL-6 (Figure 6B). By reducing the amount of GM3 present in a cell (Figure 1N), IL-6 can alleviate the suppressive effects of this ganglioside on its transcription (Figure 1L) thus setting up a 'feed-forward' loop that offers an mechanistic explanation for the self-activation of IL- 6 described in the literature [50] and demonstrated for hEBD LVEC cells in this study (Figure 6C). Figure 6C shows that levels of TLR4 mRNA also increased significantly in IL-6 supplemented cells consistent with the removal of concomitant inhibitory effects of GM3 on TLR4 [38]. Together with the impact of SMF on IL-6 shown in Figure 3, these results demonstrate that SMF has the capacity for tuning IL- 6 signaling by adjusting the relative proportions of the 'active' ganglioside GM3 and its 'inert' asialo counterpart LacCer (Figure 1K) thereby contributing to the transcriptional up-regulation of TLR4 and IL-6 (Figure $1 \mathrm{M} \& 1 \mathrm{~N}$ ).

\section{IL-6 mediated changes to GM3 and GD3 occur via NEU3 and STGAL5}

Mechanistically, changes to one of two enzymes could explain the shift in equilibrium away from the suppressive ganglioside GM3 to its inert asialo counterpart LacCer (Figure 1K); specifically, an increase in the recycling enzyme NEU3 or a decrease in the biosynthetic enzyme ST3GAL5 (Figure 7A). Despite no previously-known direct links between IL-6 and ST3GAL5 or NEU3, increased phosphorylation of ERK1/2 has been connected with the up-regulation of STGAL5 ([51], as shown in Figure $1 \mathrm{P})$. Therefore, based on a report linking IL-6 and MAPK signaling through JAK/STAT that involved ERK1/2 (Figure 1R) [52], we reasoned that ERK1/2 could serve as an intermediary to connect IL-6 with ST3GAL5 expression. Accordingly, we tested the phosphorylation of ERK (Figure $7 \mathrm{~B}$ ) and found that pERK1/2 was inhibited by concentrations of IL-6 $>4.0 \mathrm{ng} / \mathrm{ml}$ (Figure 7C); the reduced ratio of $\mathrm{pERK} 1 / 2$ to ERK was consistent with dampened mRNA levels for the biosynthetic enzyme ST3GAL5 and the tandem up-regulation of the recycling enzyme NEU3 (Figure 7D). A noteworthy aspect of this study was that, although the effects of NEU3 and ST3GAL5 on "lubricating signaling pathways" [49] have been previously evaluated separately, to our knowledge this is the first report where both enzymes were monitored simultaneously and found to respond to an external stimulus in a concerted manner that required transcriptional regulation of the biosynthetic and recycling enzymes in opposite directions.

The prolonged down-regulation of ganglioside GM3 upon IL-6 supplementation (Figure 6A) provides a twopronged mechanistic explanation for long term attenuation of IL- 6 and related responses in SMF-treated cells (for example, SMF-enhanced IL-6 levels returned to normal by day 6 (Figure 3B) followed by loss of growth inhibition by day 9 (Figure 4B)). First, the loss of sialic acid - an important contributor to the carbohydrate-carbohydrate binding interactions that stabilize lipid assemblies [48] - from GM3 can destabilize CD82-enriched microdomains [53]. Assuming that the TLR4 receptor complex, which is also sensitive to the stability of its local microdomain environment [19], responds to a reduction in GM3 levels in a similar manner, the signaling pathways activated by SMF over the first day or so of exposure could be 'turned off' by the loss of GM3 over longer time periods. A second mechanism to explain ganglioside-mediated attenuation of IL- 6 can be postulated based on the findings by Müthing and colleagues that GSL such as GM3 increase $\mathrm{Ca}^{2+}$ flux through voltage gated channels [54]. In an independent 
(A)

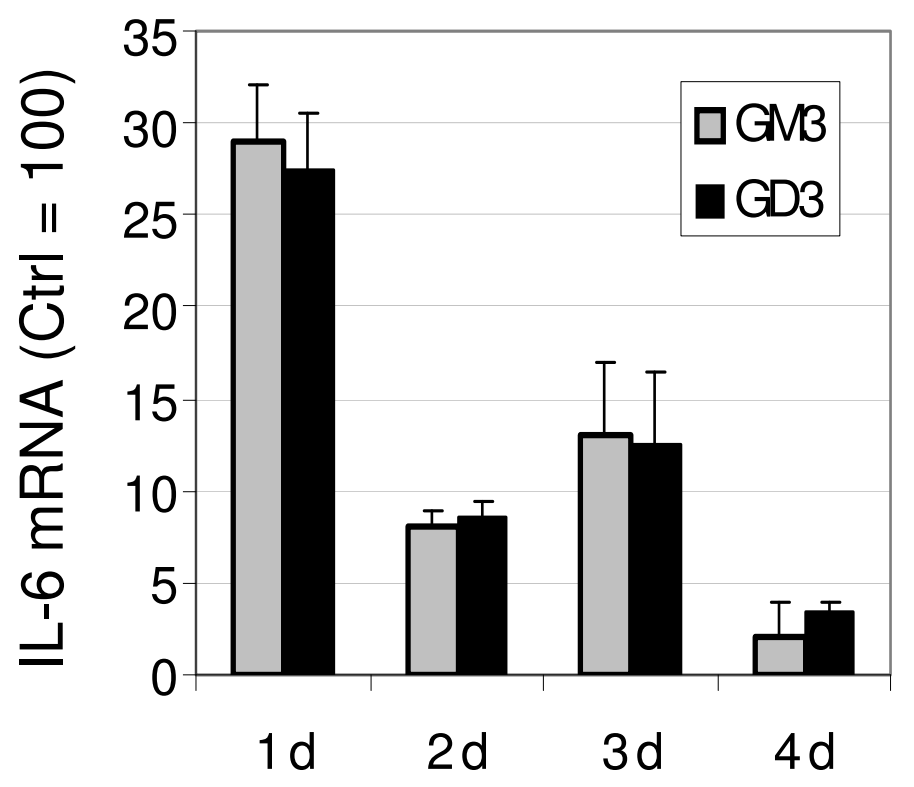

Duration of Ganglioside Exposure
(C)

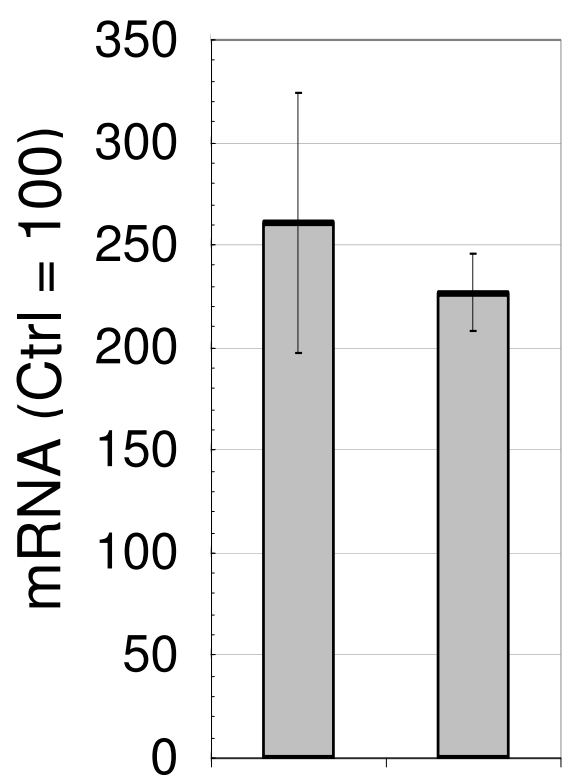

TLR4 IL-6

(B)
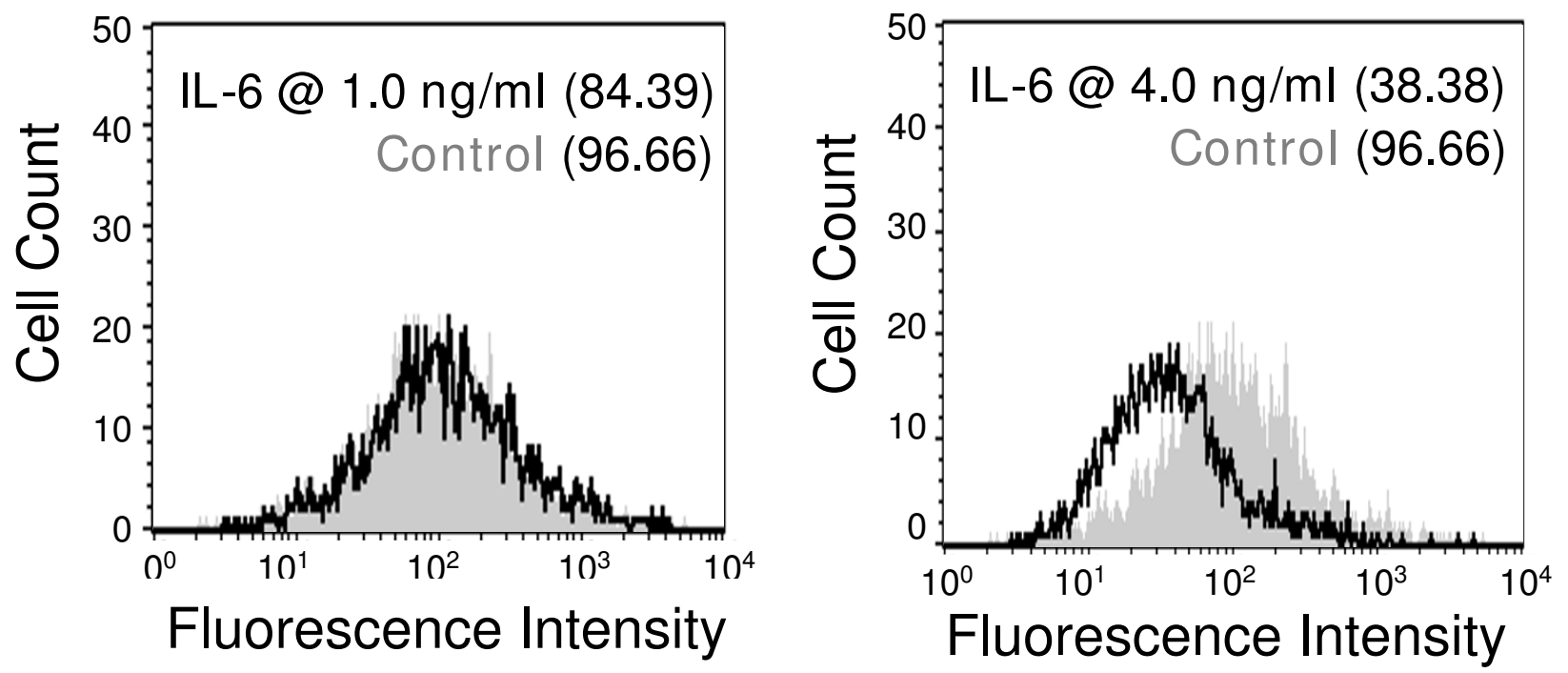

Figure 6

Crosstalk between IL-6 and gangliosides in hEBD LVEC cells. (A) IL-6 mRNA decreased upon supplementation of the culture medium with $5.0 \mu \mathrm{M}$ of either GM3 or GD3 $(n \geq 3 ; p<0.0$ I for all time points shown compared with controls that were incubated in the absence of IL-6). (B) Ganglioside GM3 decreased in a dose-dependent manner in cells supplemented with 1.0 or $4.0 \mathrm{ng} / \mathrm{ml} \mathrm{IL-6}$ for $24 \mathrm{~h}$. (C) mRNA levels for IL-6 and TLR-4 increased in cells incubated with IL-6 (error bars represent SD for $n \geq 3$ independent experiments and $p<0.05$ for both measurements). 
(A)

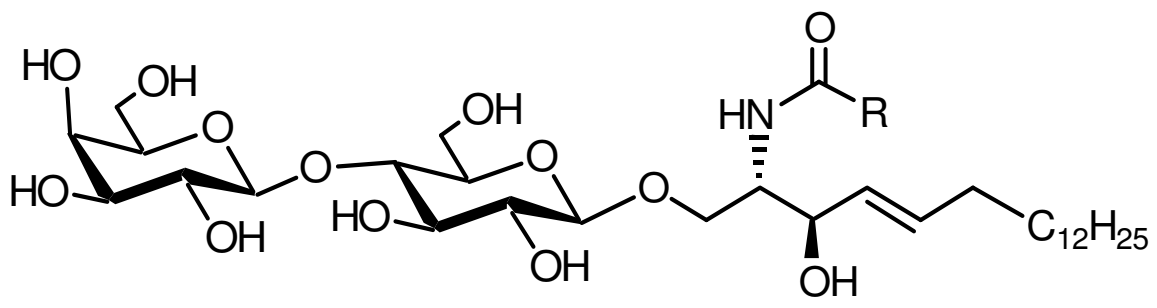

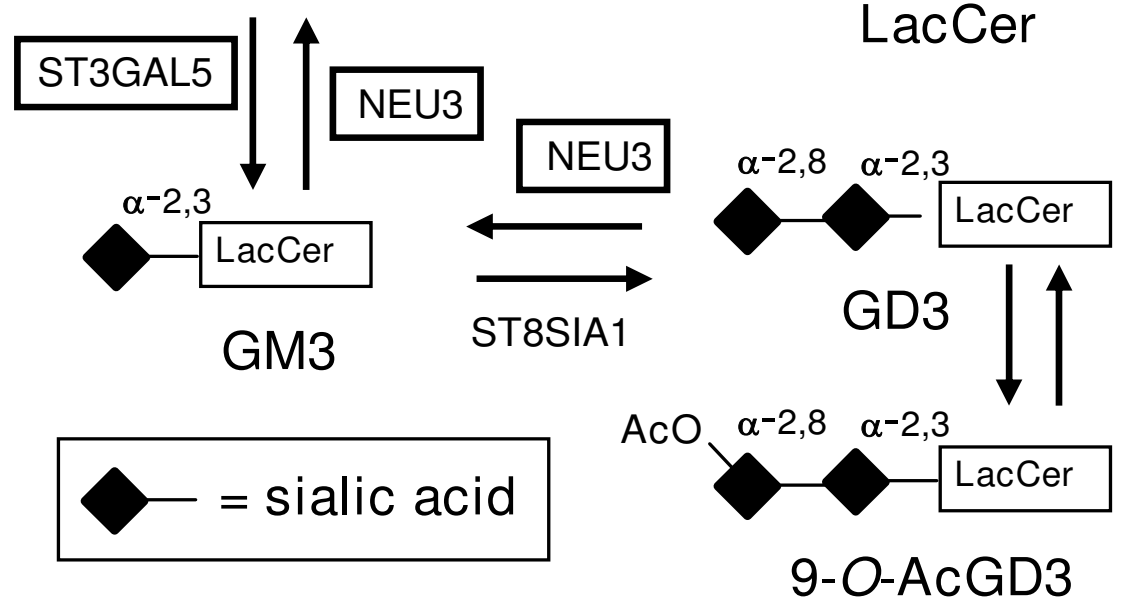

LacCer

(B)

pERK $1 / 2$

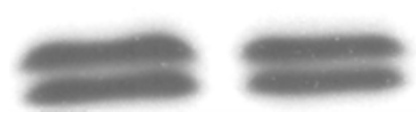

(D)

ERK $1 / 2$

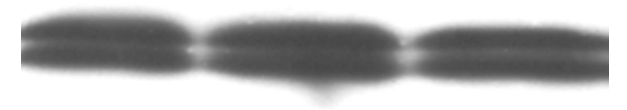

(C)

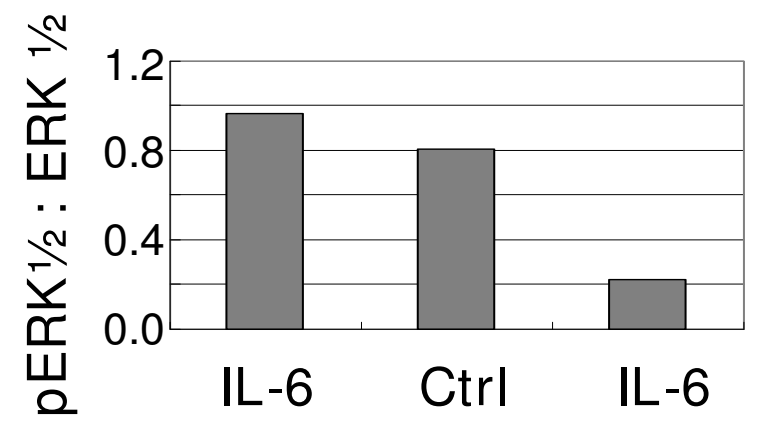

(4 ng/ml)

(8 $\mathrm{ng} / \mathrm{ml})$

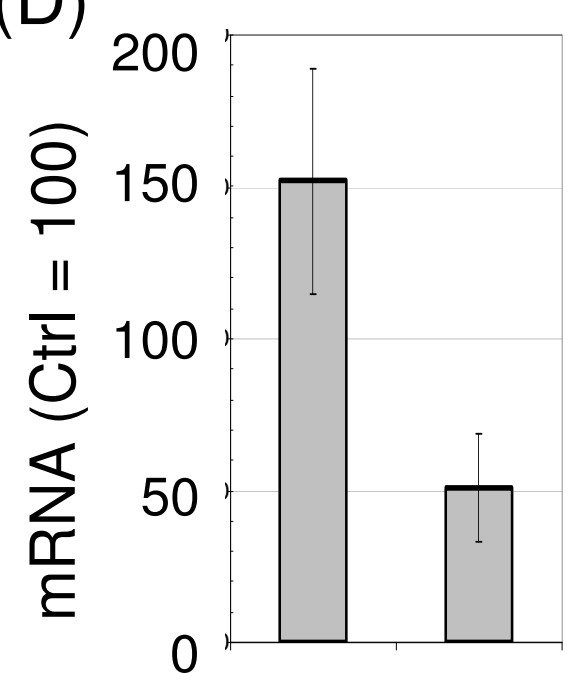

NEU3 ST3GAL5

\section{Figure 7}

Ganglioside metabolism and connections with ERKI/2. (A) This diagram shows the conversion of LacCer to the ganglioside GM3 by ST3GAL5 (and then to GD3 upon $\alpha-2,8$-sialylation and to 9-O-AcGD3 upon O-acetylation); both GM3 and GD3 are converted back to LacCer by NEU3. (B) Western blots of ERKI/2 and pERKI/2 from control and IL-6-treated hEBD LVEC cells (for $30 \mathrm{~min}$ ) show reduced ERKI/2 phosphorylation at concentrations $>4 \mathrm{ng} / \mathrm{ml}$ (as quantified by densitometry and shown as a ratio of PERKI/2 to ERK in Panel C). (D) IL-6 treated cells exhibited increased levels of NEU3 mRNA and decreased levels of ST3GAL5 mRNA after 24 h (error bars represent SD for $n \geq 3$ independent experiments and $p<0.05$ for both data sets). 
set of experiments, Yang and coworkers reported a strongly stimulatory effect for GM3 on the SR Ca ${ }^{2+-A T P a s e}$ [55-58]. Together, these findings indicate that the conversion of GM3 to LacCer in SMF-treated cells inhibits $\mathrm{Ca}^{2+}$ dependent signaling pathways in a manner that attenuates the initial multi-pronged up-regulation of IL-6.

\section{SMF regulates ganglioside production via NEU3 and ST3GAL5}

The crosstalk between gangliosides and IL-6 (as summarized in Figures $1 \mathrm{~L} \& 1 \mathrm{~N}$ and $7 \mathrm{~A}$ ), combined with the ability of SMF to modulate this cytokine (as shown by the data in Figure 3), led us to consider whether SMF altered IL-6 via a ganglioside-mediated route (or vice versa). To investigate this possibility, NEU3 and ST3GAL5 - the enzymes that control the equilibrium between GM3 and LacCer (Figure 7A) and thus have the potential to indi-
(A)

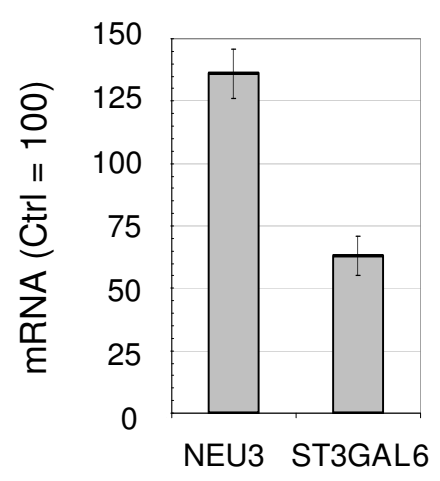

(D)

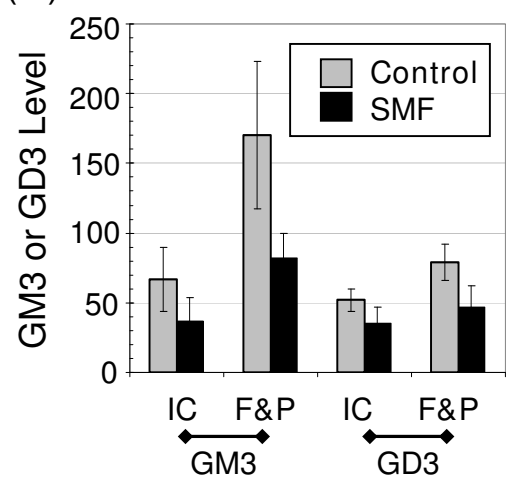

(B)
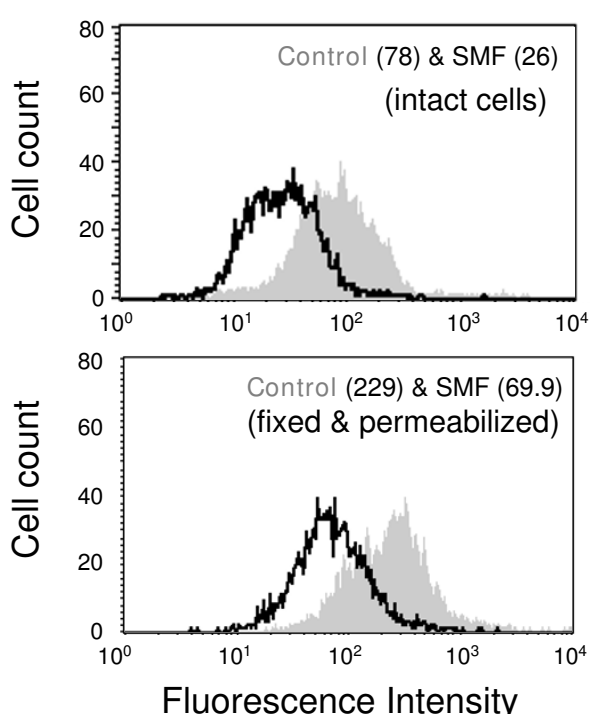

(E)

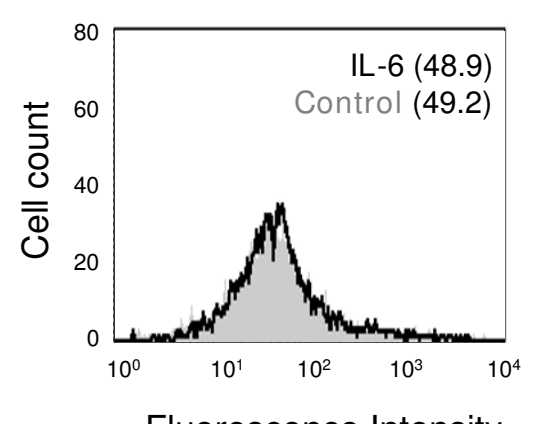

Fluorescence Intensity
(C)

GD3 (and 9-O-Ac-GD3)
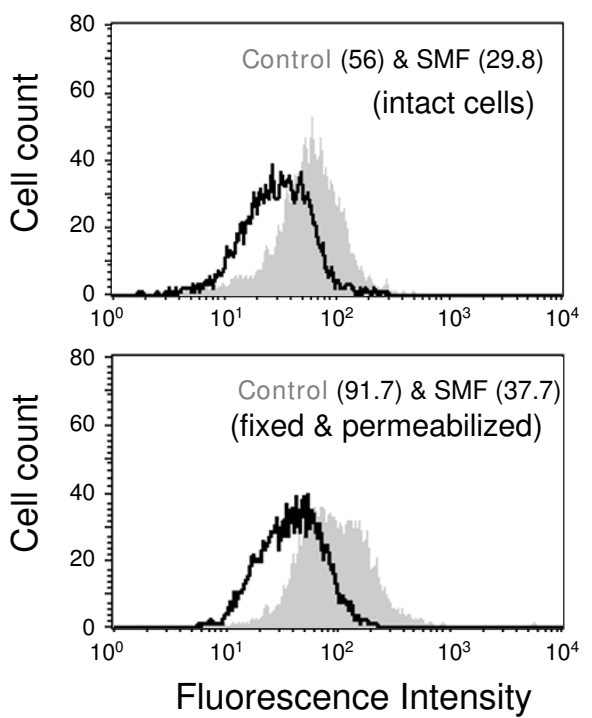

$(\mathrm{F})$

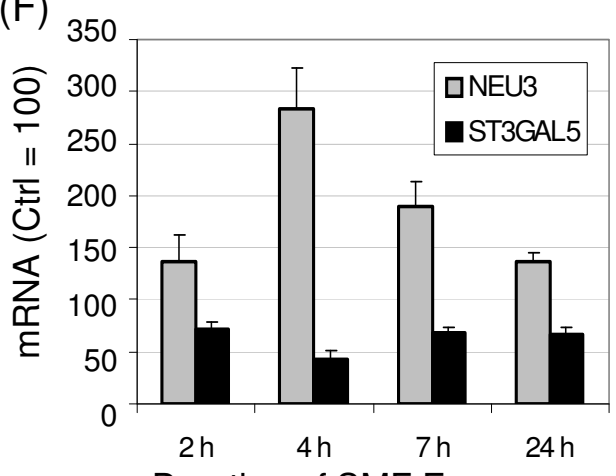

Duration of SMF Exposure

\section{Figure 8}

Effects of SMF on gangliosides GM3 and GD3 and IL-6. (A) mRNA levels increased for NEU3 and decreased for ST3GAL3 during the first 24 hours of SMF exposure consistent with a flow cytometry-measured reduction in GM3 (Panel B) and GD3/9-O-AcGD3 levels (the antibody used recognized both the 9-0-acetylated and hydroxyl forms of GD3, Panel C). (D) Data from three independent flow cytometry experiments are summarized; GM3 or GD3 levels are given as measured in the arbitrary units shown on the $\mathrm{X}$-axis of Panels $\mathbf{B}$ and $\mathbf{C}$. (E) IL-6, which led to a decrease in ganglioside levels in naïve cells (see Figure 6A) had no further effect on GM3 levels (or GD3 levels, not shown) in SMF-treated cells. (F) A time course of NEU3 and ST3GAL5 shows up- or down-regulation, respectively, over time points shorter than $24 \mathrm{~h}$. Error bars for Panels $\mathbf{A}$, D, and F represent SD for $n \geq 3$ independent experiments and $p<0.05$ for all data points that compare SMF-treated samples with the matched untreated controls. 
rectly modulate IL-6 (Figure $1 \mathrm{~L} \& 1 \mathrm{~N}$ ) - were monitored by qRT-PCR during the early stages of SMF exposure. In these experiments, up-regulation of NEU3 and inhibition of ST3GAL5 after one day of SMF exposure (Figure 8A) reminiscent of the effects of IL-6 supplementation (Figure 7D) were observed. Analysis of ganglioside levels in these cells showed that these transcriptional changes again worked in concert to decrease GM3 levels on the cell surface (Figure $8 \mathrm{~B}$, top). A similar reduction in GM3 occurred in fixed and permeabilized cells where gangliosides situated in the secretory pathway are also measured (Figure 8B, bottom). By testing both conditions, the possibility that surface changes merely reflected the redistribution of GM3 between the cell surface and intracellular compartments was discounted (this concern was raised by the hypothesis that SMF changes the biophysical properties of lipid bilayers thereby potentially affecting trafficking between surface and intracellular membranes). Interestingly, GD3 which can modulate the biophysical properties of membrane raft assemblies similar to GM3 (and in essence serves as a reservoir for this monosialylated ganglioside, Figure 7A) - was also reduced by SMF (Figure 8C); this result can be explained by the ability of NEU3 to remove both sialic acid residues of GD3.

\section{SMF regulates NEU3 and ST3GAL5 independently of IL-6} In order to gain insight into the cause and effect relationships that connect SMF, gangliosides, and IL-6, IL-6 was added to cells in the presence or absence of SMF. In this experiment IL- 6 had the same effect on GM3 levels with or without concomitant magnetic exposure (Figure 8E). This result contrasted with the clear reduction in GM3 when IL- 6 had been added to cells in the absence of SMF (as shown in Figure 6A). One explanation for these disparate results was that $\mathrm{SMF}$ activated a sequence of events where IL-6 transcription was first up-regulated leading to increased protein secretion, which in turn reduced GM3. This scenario, however, was discounted by a time course of NEU3 and ST3GAL5 mRNA expression over the first day of SMF exposure (Figure $8 \mathrm{~F}$ ) that showed that the transcriptional changes to these enzymes occurred before measurable IL-6 secretion took place (e.g., before $7 \mathrm{~h}$, see Figure 3B). Therefore, SMF independently regulates IL-6 and gangliosides in a way that ultimately impinges on the same molecular mechanism (i.e., through NEU3 and ST3GAL5 transcription and activity). GM3 and GD3 also provide a putative explanation for the biphasic increase in IL-6 mRNA; at early time points a ganglioside-independent sequence of events (presumably involving, but not necessarily limited to, TLR4 activation or $\mathrm{Ca}^{2+}$ flux) occurs. As the initial signal fades, reduction of GM3 and GD3 could contribute to a second 'burst' of IL-6 expression by alleviating the suppressive effects of these gangliosides on IL-6 itself (Figure 1L) or on TLR4 (Figure 1M).

\section{SMF - in combination with IL-6 - alters cell morphology}

As described earlier, hEBD LVEC cells exposed to SMF experienced reduced proliferation without toxicity (Figure 4), a response consistent with differentiation. To test if this phenomenon was linked to SMF or IL- 6 production, cells were first treated with $\leq 4.0 \mathrm{ng} / \mathrm{ml}$ of IL- 6 in the absence of SMF. IL-6 supplementation typically resulted in relatively minor (if any) change to cell morphology (Figure 9A\&9B). Occasionally, however, dendrite-like outgrowths reminiscent of neuronal cells developed in sub-populations of IL- 6 treated cells (Panel C). By contrast, close to $100 \%$ of the cells attained distinctive morphology when SMF was combined with $4.0 \mathrm{ng} / \mathrm{ml}$ of IL- 6 (Panel E; SMF alone had a much less pronounced impact on morphology, Panel D).

One explanation for why both SMF and exogenous IL-6 supplementation was needed to elicit noticeable changes to cell morphology was that, because of the relatively small volume of cells $(\leq 0.01 \%$ ) compared to culture medium, any IL-6 secreted in response to SMF would be diluted 10,000-fold. As a consequence, additional IL-6 supplementation was required to mimic levels achieved by comparable rates of IL-6 production in cells situated within an in vivo niche where the relative cell to interstitial volume ratios are much lower. Another (non-exclusive) explanation, supported by experiments where even $20 \mathrm{ng} /$ ml IL- 6 could not reproduce the combined effects of SMF plus $4 \mathrm{ng} / \mathrm{ml}$ IL-6 (data not shown), was that SMF-activated networks beyond IL-6 - such as those listed in Table 5 - contributed to the morphological changes.

\section{SMF promotes oligodendrocyte progenitor markers}

To gain greater insight into the morphological changes induced in hEBD LVED cells by a combination of SMF and IL-6, we noted that IL- 6 has a role in the regeneration of nervous tissue, usually promoting astrocyte formation [35] and, accordingly, monitored the transcription of bone morphogenic protein 2 (BMP-2) and myelin basic protein (MBP) (Figure 9F). Interestingly, a decrease in mRNA for BMP-2, a protein that stimulates astrocytogenesis [59], was observed suggesting that the hEBD cells were not differentiating into astrocytes as expected. To confirm this observation using immunofluorescent microscopy, no increase in the GFAP marker associated with astrocyte formation was observed in SMF and IL-6 treated cells (Figure 10A). Similarly, no increase was seen for NEF (Figure 10B), a marker associated with neuron differentiation.

Based on the lack of astrocyte or neuron differentiation, a third possibility was that the decrease in BMP-2 expression in SMF-treated cells removed the obstacle presented by bone morphogenetic proteins towards differentiation to oligodendrocyte lineages [60]. Indeed, consistent with 

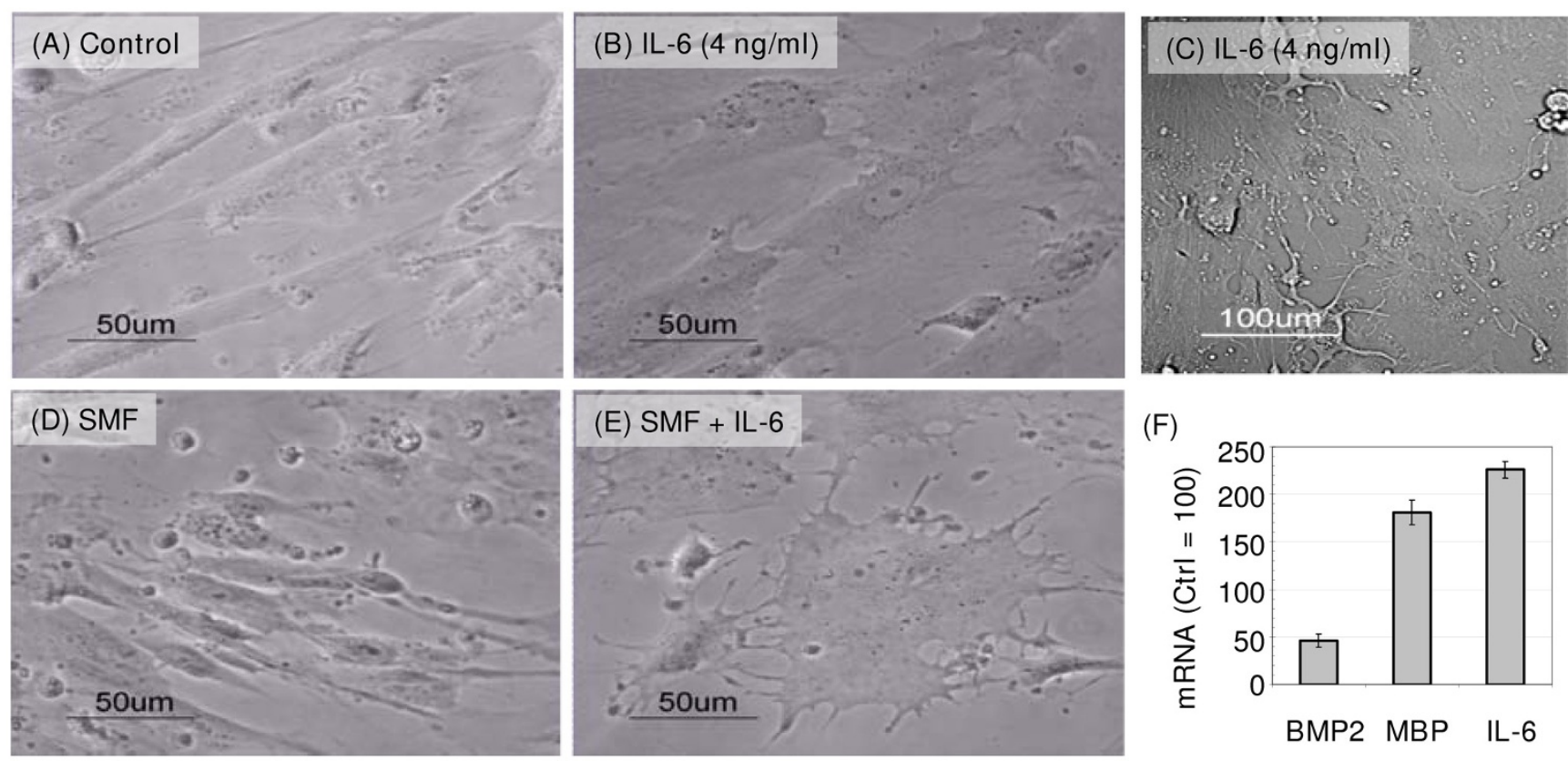

(F)

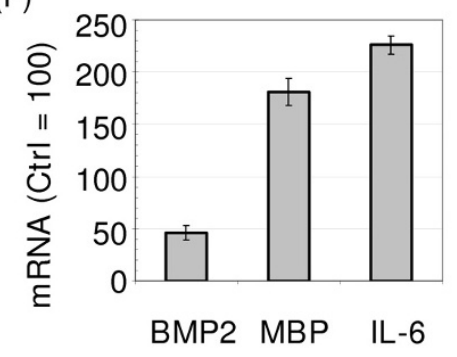

\section{Figure 9}

Morphological effects of SMF and IL-6 on hEBD LVEC cells. (A) Phase contrast images showing the normal morphology of $\sim 90 \%$ confluent hEBD LVEC cells. (B) Slightly altered morphology typically was seen after incubating the cells with 4.0 $\mathrm{ng} / \mathrm{ml}$ of IL-6 for 3 days. (C) Cells incubated with $4.0 \mathrm{ng} / \mathrm{ml} \mathrm{IL-6}$ sporadically attained dramatically altered cell morphology, with neurite-like outgrowths. (D) SMF, by itself, had a minor impact on the morphology of hEBD LVEC cells. (E) The combination of SMF and $4.0 \mathrm{ng} / \mathrm{ml} \mathrm{IL-6}$ resulted in $\sim 100 \%$ of the cells attaining the distinctively altered morphology shown. (F) mRNA levels of bone morphogenetic protein 2 (BMP2), myelin basic protein (MBP), and IL- 6 after $24 \mathrm{~h}$ of SMF exposure (error bars represent SD for $n \geq 3$ independent experiments and $p<0.05$ for each marker).

the decrease in BMP-2, an increase in myelin basic protein (MBP) transcription was observed (Figure 9F) providing a biochemical marker consistent with differentiation to an oligodendrocytes [61]. Additional supporting evidence that SMF, combined with IL-6, leads toward oligodendrocyte progenitor formation was provided by the increased expression of vimentim (Figure 10C) and Gal-C (Figure $10 \mathrm{D})$.

\section{A timeline of SMF responses: Towards unraveling cause and effect relationships}

The relationships between SMF, calcium, TLR4, gangliosides (and regulatory enzymes), MAPK pathway elements (p38 and ERK1/2) and IL-6 are outlined in Figure 1; this diagram, however, does not provide a dynamic view that would provide insight into cause and effect relationships. Therefore, to summarize the time dependence of various aspects of hEBD LVEC cell responses to SMF exposure, early, intermediate, and longer term responses are summarized in Figure 11. During the first four hours (Panel A), changes to calcium flux occur within minutes as do MAPK responses (e.g., p38 phosphorylation, Figure 4A); effects on the transcription of IL-6, TLR4, NEU3, and ST3GAL5 mRNA lag slightly but show a strong response beginning between 2 and 4 hours. By contrast, secreted IL6 remains unchanged. During the remainder of the first day of exposure (Panel B), mRNA levels of SMF treated cells trend back to control levels (the one exception is the 24 hour point for IL-6, which rebounds after a decline between 4 and 7 hours, this biphasic response mimics the impact of other stimuli on IL-6 [36]). Also during the first day, while the impact of SMF on transcription of IL- 6 , TLR4, NEU3, and ST3GAL5 abates, phenotypic effects such as the accumulation of measurable levels of secreted IL- 6 began to be manifest. In general, initiating events for example, the impact of SMF on mRNA levels - were attenuated after the second day (as shown in Panel C) whereas "behavioral" responses (such as the secretion of IL-6 or the effects of SMF on proliferation) followed the same trend but lagged in time. During this multiday time period - while "intermediate" responses were returning to normal - long-lived changes to cell fate arose that included the morphological changes shown in Figure 9 and the accumulation of pre-oligodendrocyte markers shown in Figure 10.

Another lesson learned from the data shown in Figure 11 was that SMF treatment set in motion a complex sequence 
(A) GFAP (glial fibrillary acidic protein)
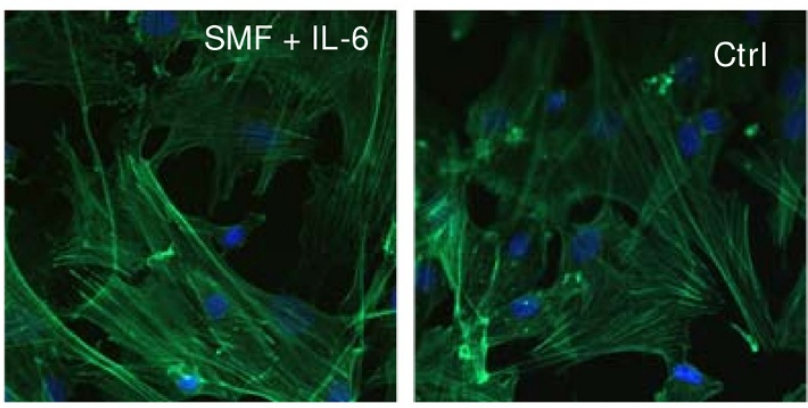

(B) NEF: neurofilament $70 \mathrm{kDA}$
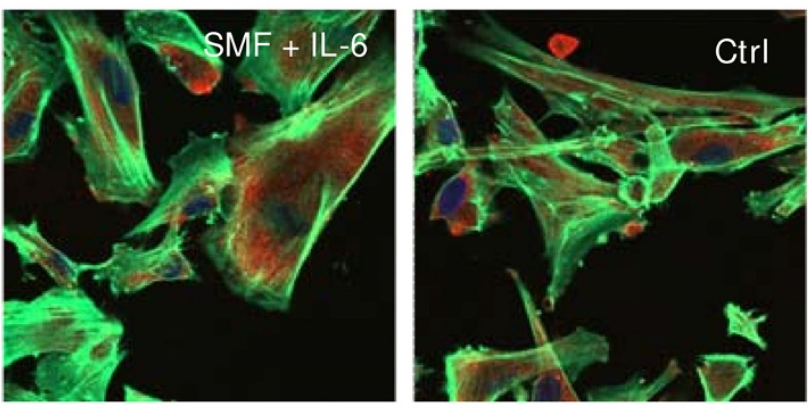

(C) Vim: vimentim
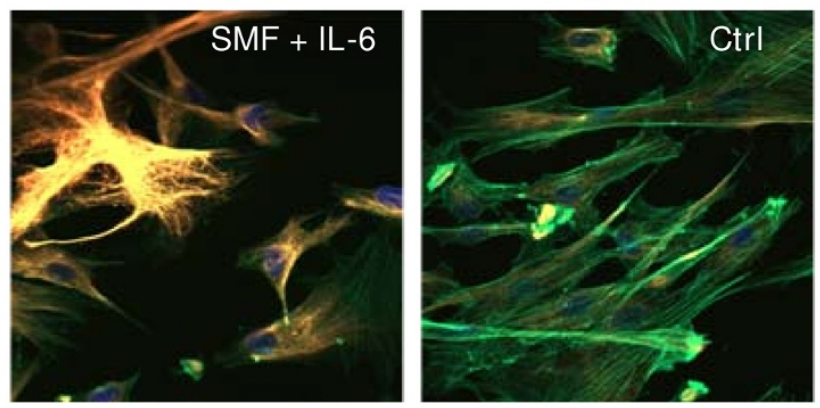

(D) Gal-C: galactocerebroside
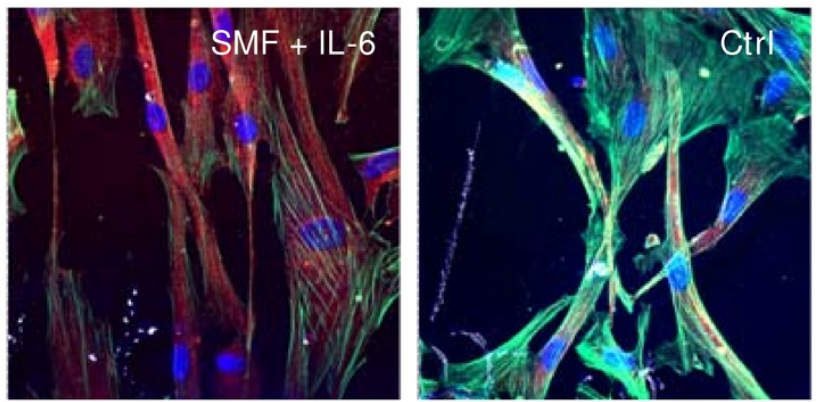

Figure 10

Differentiation markers in SMF- and IL-6-treated hEBD LVEC cells. Test cells were incubated with $4.0 \mathrm{ng} / \mathrm{ml}$ IL-6 with concurrent SMF exposure (controls were incubated with neither) and the monolayers were co-stained with Oregon Green 488 phalloidin to visualize actin, the nuclear dye DAPI (blue), and one of the following markers (red): (A) the astrocyte marker GFAP (note that the lack of staining indicates the absence of this marker in both treated and control cells); (B) the neuron marker NEF; and the pre-oligodendrocyte markers (C) Vim and (D) Gal-C. Images were obtained by confocal microscopy using identical exposure settings for each set of photographs.

of events that rapidly changed over time; consequently, the original goal of analyzing cellular responses by microarray profiling could have led to erroneous conclusions. For example, the complex and rapidly changing nature of IL-6 mRNA transcription could have led to the conclusion that the microarray results were simply irreproducible, as has been reported for much lower-strength fields [62]. Alternately, the four and five day time points - where IL6 mRNA levels were actually lower than controls - were not consistent with the strong, multifaceted up-regulation that occurred upon the initial exposure to magnetic stimulus thereby also providing misleading information if regarded in isolation. Therefore, we close by noting the benefits of the robust ability of software tools to uncover signature biological activity - namely, signaling responses associated with IL- 6 - even when the key molecular player (i.e., IL-6) is undergoing rapidly changing or oscillatory behavior that would be difficult to understand by itself.

\section{Conclusion}

At the outset, we emphasize that this study was not intended to provide a comprehensive account of the cellular effects of SMF. For example, mechanisms other than those based on a lipid biolayer 'biosensor' may contribute to the transcriptional changes observed in this study as direct effects of SMF on protein-DNA interactions have been postulated [63-66] as have changes in enzymatic and biochemical reactions [5,67-69]. Therefore, we reiterate that our goal was to provide a rudimentary framework of one of many parallel or complementary mechanisms through which magnetic stimuli are transduced from molecular level biosensors into cell-level responses. This objective was pursued by mRNA microarray profiling that verified time-dependent global changes in transcription occurred that were consistent with the activation of signaling pathways. Then, to gain insight into the specific networks affected by SMF exposure, which were not obvious by simple inspection of the genes involved, the microarray data was subject to software analysis and signaling networks consistent with tissue- or organ-level responses to 
(A) Early responses

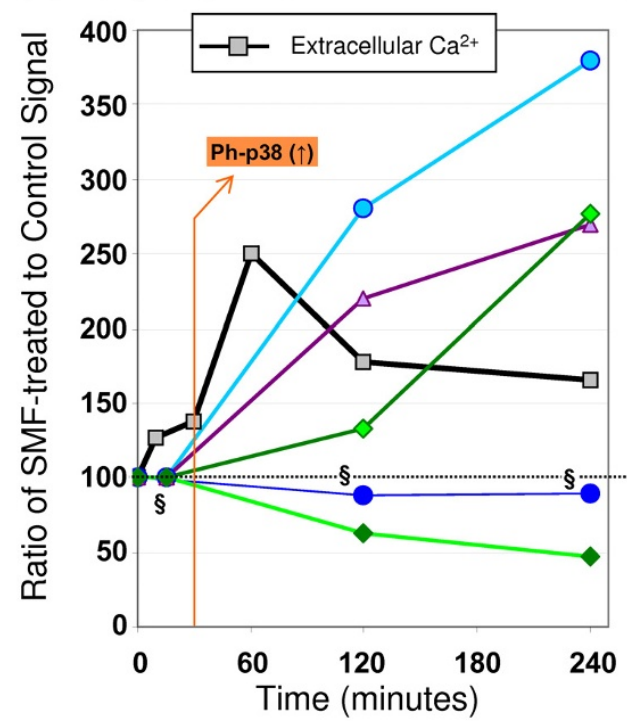

(B) Intermediate responses

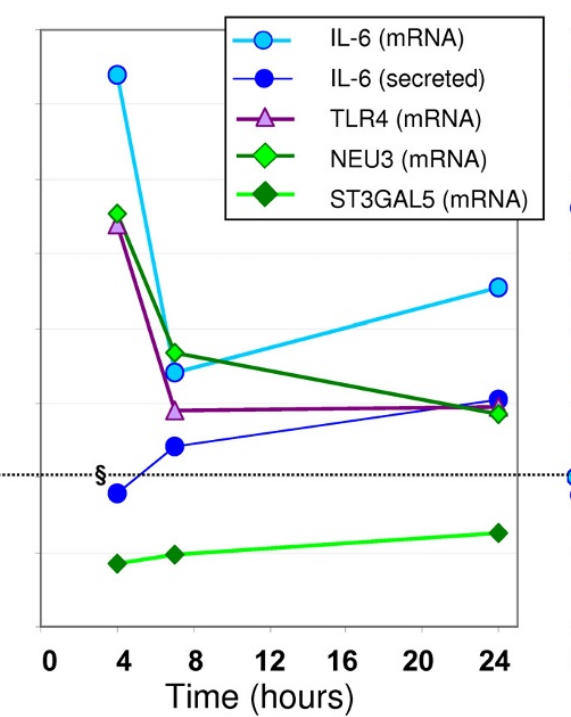

(C) Longer term responses

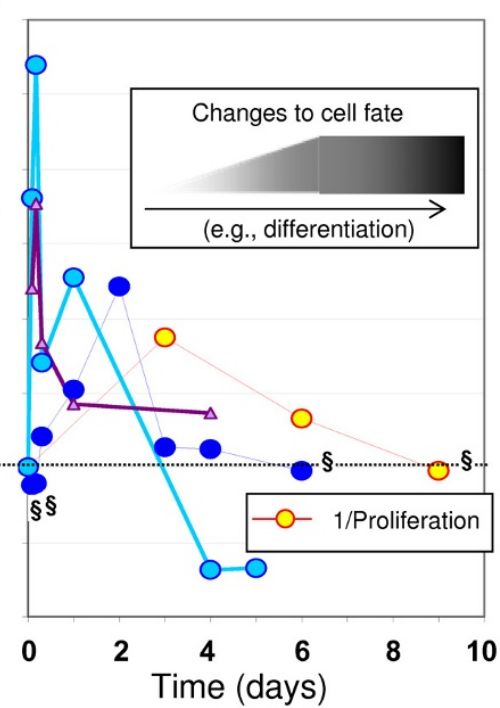

Figure I I

Timeline of SMF-induced, IL-6 associated responses in hEBD LVEC cells. Data is compiled from experiments reported throughout this paper to show $(\mathbf{A})$ early responses that occur within four hours of the start of continuous SMF exposure, $(\mathbf{B})$ intermediate responses that occur over the first day, and (C) longer term responses over the first week or so of SMF exposure. Data is shown for $n \geq 3$ independent experiments and $p<0.05$ for all data except for that indicated by " $\$$ " where $p$ $>0.05$ (these data were analyzed by SD but error bars are omitted from these graphs for clarity). All data shown - except for the proliferation data in Panel $\mathbf{C}$ that gives the reciprocal relationship - compares SMF-exposed to control cells with a value of 100 as a baseline.

magnetic exposure (that include benefits to wound healing [11] and inflammation [12]; cardiovascular effects [13] such as modulation of blood flow and pressure [10]; and anti-tumor activity $[70,71])$ were identified.

Although the microarray data identified cellular responses consistent with previously reported biological responses to magnetic exposure, we nonetheless sought to ensure that these associations were not just coincidental or an artefact of the software analysis. Detailed biochemical investigation of all nine pathways (see Table 5) was well beyond the scope of a single study, therefore we selected a single network - IL-6 signaling - for validation and outlined several molecular paths (as shown in Figure 1) that accounted for the multifaceted up-regulation of IL- 6 by SMF that occurred over the first 1 to 3 days of exposure. From the standpoint of disease intervention, the up-regulation of IL- 6 by SMF at first seems to be unwanted because IL- 6 is generally maintained at low levels in healthy tissue [50]. Moreover, chronically elevated levels of IL- 6 are usually deleterious (for example, inflammation and unabated astrocyte differentiation associated with increased IL-6 experienced after brain or spinal cord injury blocks axonal regeneration of neurons and thereby hampers full recovery [35]). In some cases, however, the shortterm activation of IL- 6 can be therapeutically beneficial; for example, this pleiotropic cytokine can be neuroprotective immediately after injury [28]. Consequently, successful therapeutic intervention involving IL-6 is contingent upon transient - as experienced in the SMF-treated cells rather than on prolonged activation to avoid the deleterious consequences of chronic inflammation and other long term consequences of sustained IL- 6 production.

In a final set of experiments, we briefly investigated whether SMF-mediated responses associated with IL-6 signaling translated into changes in phenotype observable at the whole cell level. Although IL-6 impacts numerous celllevel and systemic responses, our experimental efforts were focused by reports that IL- 6 guides differentiation of neural stem cells primarily to astrocytes [35]. These clues led us to investigate whether evidence of astrocytogenesis was seen in the hEBD LVEC cells, an embryonic line that is predisposed to neural differentiation [24]. Interestingly, responses consistent with differentiation (i.e., slowed proliferation and morphological changes) were not reflected in the biochemical markers indicative of the astrocyte differentiation expected from IL-6. Instead, markers found in oligodendrocyte precursor cells were manifest, indicating that the other pathways modulated by SMF tuned the 'usual' activity of IL-6. Ultimately, if full oligodendrocyte formation can be promoted in vivo by SMF without con- 
comitant astrocyte enhancement (under the current experimental conditions, full differential to oligodendrocytes was not feasible due to the absence of neurons and other glial cells found in the in situ oligodendrocyte microenvironment), this capability could lead to noninvasive therapies for conditions such a multiple sclerosis (MS) linked to oligodendrocyte pathologies.

\section{Methods \\ Cell lines and culture conditions}

The human embryoid body derived (hEBD) LVEC cell line [24] was obtained from the Shamblott Laboratory (JHMI) and was cultured in EGM2MV media (Clonetics, San Diego, CA) that included 5.0\% fetal bovine serum (FBS), hydrocortisone, human basic fibroblast growth factor, human vascular epidermal growth factor, R(3)-insulinlike growth factor I, ascorbic acid, human epidermal growth factor, heparin, gentamycin, and amphotericin. The HEK AD293 line was obtained from the ATCC (Manassas, VA) and incubated in DMEM supplemented with $10 \%$ FBS under established conditions [72]. Cells were cultured on tissue culture (T.C.) plastic coated with bovine collagen I (Collaborative Biomedical Products, Bedford, MA; $10 \mu \mathrm{g} / \mathrm{cm}^{2}$ ) in a water-saturated, $37^{\circ} \mathrm{C}$ incubator with $5.0 \% \mathrm{CO}_{2}$.

\section{Exposure of cultured cells to SMF}

Cell exposure to SMF was conducted for time intervals up to a maximum of 9 days using a device obtained from the Advanced Magnetic Research Institute, International (AMRIi, Calgary, AB) that fit into a standard T. C. incubator with sufficient clearance on all sides so that incubator functions (i.e., circulation of $\mathrm{CO}_{2}$ and water saturated air) were not affected. The device was designed based on principles derived from clinical testing of SMF (Diabetic Peripheral Neuropathy (ClinicalTrials.gov Identifier: NCT00134524) and Chronic Low Back Pain (NCT00325377)) that the magnetic field must be unidirectional with no reverse field passing through the sample [73]. It was embedded with four $1 " \times 4 " \times 6 "$ (inch) permanent neodymium (NdFeB) rectangular block magnets with two located above and two below the central cavity (Additional file 2: Figure S10). The device produced a field with a magnetic flux gradient of $<1.0 \mathrm{mT} / \mathrm{mm}$ in the portion of the central cavity where the cells were maintained during experiments. This arrangement contrasts with experimental set-ups where each well of a T. C. plate has been supplied with SMF exposure by using a separate magnet; in these cases (or in experiments specifically designed to test gradient responses) the periphery of the treatment areas were subject to much higher magnetic flux gradients of 20,21 , or $28 \mathrm{mT} / \mathrm{mm}[31-33,74]$ that resulted in different cellular responses than observed in the more uniform portions of the magnetic fields.
As just explained, the SMF conditions used in the current experiments were not expected to elicit gradient effects because the gradient used was much shallower than previously reported (i.e., $<1.0 \mathrm{mT} / \mathrm{mm}$ compared to $20-28$ $\mathrm{mT} / \mathrm{mm}$ ). Nevertheless, to ensure that gradient effects - or other artefacts of the exposure conditions - did not account for the effects observed in hEBD LVEC cells in this study, several control experiments were conducted. First, the direction of the flux (i.e., whether the device was oriented upright so that the field was superimposed on the Earth's magnetic field or oriented upside down so that the applied field countered the background field) was tested and found not to have an impact on the parameters under investigation in hEBD LVEC cells. Second, differences in field strength (i.e., whether the cells were exposed to field at the extreme top or bottom of the treatment device when six T. C. plates - the maximum capacity of the device were stacked on top of each other) did not measurably affect the outcome of the experimental parameters reported in this study. Finally, the orientation of the T. C. plates (e.g., whether the plates were placed as shown in Figure S10 (Additional file 2) or at $90^{\circ}, 180^{\circ}$, or $270^{\circ}$ angles) did not alter experimental outcomes.

Despite the lack of variation in IL- 6 related outcomes, the experiments described in this report were always performed with the induced static magnetic field superimposed in the same direction as the ambient field, the SMFtreated cells were maintained in the central portion of the device oriented as shown in Figure S10 (Additional file 2) in the region the where magnetic flux density ranged between 0.23 and $0.28 \mathrm{~T}$ (as measured by a gaussmeter, Type 181002, Thyssen Magnet-und komponententechnik, Dortmund, Germany). Control cells were kept in an identical incubator where the ambient magnetic field was $\sim 52 \mu \mathrm{T}$ (which was within $1 \mu \mathrm{T}$ of the background levels measured by us or reported by the National Geophysical Data Center for the location where these experiments were conducted (i.e., 52,359.0 nT at a latitude of $39^{\circ} 19^{\prime}$ $35^{\prime \prime}$ and a longitude of $-76^{\circ} 36^{\prime} 17^{\prime \prime}$,. http:ngdc.noaa.gov/geomagmodels/ IGRFWMM.jsp?default Model=IGRF).

\section{Transcriptional (mRNA) profiling}

In all cases, the cells subjected to microarray profiling were obtained from the same initial culture batch and were subsequently cultured for a total of six days before RNA was isolated and analyzed. Subconfluent $(70 \%-$ $80 \%$ ) undifferentiated hEBD LVEC (passage 11) cells were trypsinized, resuspended, and replated at $5.0 \times 10^{5}$ cells in $10 \mathrm{ml}$ medium in $10 \mathrm{~cm} \mathrm{~T}$. C. dishes on "Day 0". All cells were allowed to recover from the plating process by incubating them under normal culture conditions for one day after which time four conditions were investigated. For Group 1, control cells were incubated for five additional 
days under normal culture conditions. For Group 2, cells were cultured under normal conditions for four additional days and then subjected to one day ( $\sim 24 \mathrm{~h}$ ) of SMF exposure in the magnetic treatment device on "Day 6"; mRNA from these cells, as well as from the third group, was isolated for analysis immediately after magnetic exposure ended. For Group 3, cells were subjected to continuous SMF exposure for five days. Finally, for Group 4, cells were exposed to SMF for four days (from Day 2 through Day 5) followed by a $24 \mathrm{~h}$ recovery period during which time they were incubated under normal culture conditions. mRNA was isolated from the cells and microarray analysis was done using the Affymetrix Human Genome U133 2.0 Plus Chip using the protocols and facilities available through the Johns Hopkins Cancer Center Microarray Core. All data was obtained in duplicate from independent experiments. Software analysis was performed using the Ingenuity Pathway tool (available through the Microarray Core) using merged data from each set of independent experiments. The microarry data have been deposited in NCBI's Gene Expression Omnibus [75] and are accessible through GEO Series accession number GSE14474 http://www.ncbi.nlm.nih.gov/geo/ query/acc.cgi?acc=GSE14474.

\section{Calcium measurements}

hEBD LVEC cells were incubated in $\mathrm{Ca}^{2+}$ - and $\mathrm{Mg}^{2+}$-free for PBS for up to four hours (longer time points decreased cell viability making the assay results unreliable) with or without SMF exposure. Intra- and extra-cellular calcium levels were measured separately after the cells were separated from their supernatants by pelleting with a $300 \mathrm{~g}, 2$ min centrifugation step followed by lysis by sonication with a GE130PB ultrasonic processor (General Electric, New York, NY). Analysis of the supernatants and cell lysates was then conducted using a calcium reagent set (Pointe Scientific Inc., Canton, MI) and published methods [76].

\section{Treatment of cells with exogenous gangliosides (GM3 and GD3)}

The basic procedure for ganglioside supplementation followed published procedures [77]. Briefly, cells were plated in 6-well tissue culture dishes and incubated until they reached $60 \%$ confluence. GM3 or GD3 (Matreya
LLC, Pleasant Gap, PA) was resuspended in serum-free medium and briefly sonicated to ensure appropriate micellar suspension and cellular incorporation of these gangliosides. Cells were then incubated in culture medium containing $1.0,5.0,10,20$, or $50 \mu \mathrm{M}$ GM3 or GD3 for varying periods of times (as specified in the Results section and accompanying figures). In each case, results were compared with a "solvent control," where an equal volume of medium was added to cells without ganglioside.

\section{Real-time PCR quantification of gene expression}

The mRNA levelsofST3GAL5, NEU3, TLR4, IL6andglyceraldehyde-3-phosphatedehydroge-

nase(GAPDH)wereanalyzedbyquantitativereal-timepolymerasechain reaction (qRT-PCR) $[77,78]$. Primers (listed in Table 6), were designed by using the Primer3 software made available through the Broad Institute http:// genecruiser.broadinstitute.org/science/software and obtained from MWG-Biotech (High Point, NC). The basic protocol followed for qRT-PCR experiments began with the isolation of total RNA from $5.0 \times 10^{6}$ cells with the RNeasy Mini Kit (Qiagen, Valencia, CA) or by the TRIzol (Invitrogen) method. RNA quality was assessed by agarose gel electrophoresis (1.8\% gels run with TAE buffer followed by nucleic acid band visualization under UV illumination after ethidium bromide staining) and quantified by $\mathrm{A}_{260} / \mathrm{A}_{280}$ OD readings. RNA integrity was confirmed using $18 \mathrm{~S}$ rRNA primers, and samples were standardized based on equal levels of $\beta$-actin cDNA. Quantitative real-time PCR was performed in an ABI Prism 7000 sequence detector (Applied Biosystems) using SYBR Green PCR Master Mix reagent (Applied Biosystems). Reactions were performed in $20 \mu \mathrm{l}$ of a mixture containing a $2.0 \mu \mathrm{l}$ cDNA dilution, $1.0 \mu \mathrm{l}(10 \mathrm{pmol} / \mu \mathrm{l})$ of primer, and $10 \mu \mathrm{l}$ of $2 \times$ SYBR master mix containing Amplitaq Gold DNA polymerase, reaction buffer, a dNTP mixture with dUTP, passive reference, and the SYBR Green I. qRT-PCR conditions were as follows: one cycle of 2.0 $\min$ at $50^{\circ} \mathrm{C}, 95^{\circ} \mathrm{C}$ for $10 \mathrm{~min}$, followed by 40 cycles of $95^{\circ} \mathrm{C}$ for $15 \mathrm{~s}$ and $60^{\circ} \mathrm{C}$ for $1.0 \mathrm{~min}$. Specific PCR products were detected with the fluorescent double-stranded DNA binding dye, SYBR Green. qRT-PCR amplification was performed in quadruplicate for each sample (typically values for the replicates were within $2 \%$ of each other)

Table 6: Primers used for qRT-PCR

\begin{tabular}{ccc}
\hline Gene & Forward primer (5' to $\left.\mathbf{3}^{\prime}\right)$ & Reverse primer (5' to 3') \\
\hline ST3GAL5 & CCC TGA ACC AGT TCG ATG TT & CAT TGC TTG AAG CCA GTT GA \\
NEU3 & CCT GAA GCC ACT GAT GGA A & TTC CTG CCT GAC ACA ATC TG \\
IL-6 & TAC ATC CTC GAC GGC ATC TC & GCT ACA TTT GCC GAA GAG CC \\
TLR4 & TGA GCA GTC GTG CTG GTA TC & CAG GG TTT TCT GAG TCG T \\
GAPDH & GCA AAT TCC ATG GCA CCG T & TCG CCC CAC TTG ATT TTG G \\
\hline
\end{tabular}


and the results were replicated in at least three independent experiments. Gel electrophoresis and melting curve analyses were performed to confirm correct PCR product sizes and the absence of nonspecific bands. The expression level of each gene was normalized against $\beta$-actin using the comparative CT method [79] according to the manufacturer's protocols.

\section{Analysis of cell surface and total levels of GM3 and GD3}

The method used for the analysis of cell surface GM3 and GD3 expression by flow cytometry was adapted from published protocols [77]. Briefly, these tests were performed by detaching hEBD LVEC cells by trypsinization and washing them with washing buffer $(1.0 \%$ bovine serum albumin, $0.1 \% \mathrm{NaN}_{3}$ in phosphate-buffered saline). Cells $\left(1.0 \times 10^{6}\right)$ were stained with $20 \mu \mathrm{g} / \mathrm{ml}$ of a mouse monoclonal antibody against GM3 (NBT-M101/M102, isotype IgM, clone M2590; Cosmo Bio Co., Ltd., Tokyo, Japan) and detected with fluorescein isothiocyanate-conjugated Affinipure rabbit anti-mouse IgM (Jackson Immunoresearch, West Grove, PA). A similar procedure was used for GD3 analysis, except cells were stained with mouse anti-human ganglioside GD3 monoclonal antibody (Product number 371440, clone 110.14F9, isotype IgG3; Calbiochem) diluted 1:50 in washing buffer and detected with a donkey anti-mouse IgG antibody conjugated to fluorescein (Jackson Immunoresearch). Control samples stained with secondary antibody alone were analyzed in parallel in each experiment. Samples were analyzed with a FACScan flow cytometer and Cell Quest software (BD Immunocytometry Systems, San Diego, CA), and a minimum of 5000 events were acquired for each sample. Analysis of total (i.e., surface and intracellular) GM3 and GD3 was tested in fixed and permeabilized cells [80] by adaptation of a method used to quantify intracellular levels of p21WAF1 [81]. Briefly, before completing the staining procedure described above, cells were fixed by incubation in $4.0 \%$ paraformaldehyde in phosphate-buffered saline for $10 \mathrm{~min}$ at room temperature followed by

\section{Western blot analyses}

An equal amount of protein from each sample $(20 \mu \mathrm{g})$ was incubated for $5.0 \mathrm{~min}$ at $100^{\circ} \mathrm{C}$ in Laemmli buffer (Bio-Rad), separated on a $7-11 \%$ SDS-polyacrylamide discontinuous gel, and then electrophoretically transferred to a nitrocellulose membrane (Bio-Rad). The membrane was blocked with Tris-buffered saline containing $5.0 \%$ nonfat milk and $0.1 \%$ Tween 20 for $1.0 \mathrm{~h}$ at room temperature and then incubated overnight with rabbit phospho-p44/42 MAPK (i.e., pERK1/2) monoclonal antibody and p44/42 MAPK (i.e., ERK1/2) antibody (1:1000 dilution) or phospho-p38 MAPK and p38 MAPK (1:2000) or phospho-stat3 (Tyr705) and Stat3 rabbit antibody (1:1000) (Cell Signaling Technology, Beverly, MA) at $4.0^{\circ} \mathrm{C}$, followed by anti-rabbit or anti-mouse IgG, horseradish peroxidase-linked antibody (1:2000) for $1.0 \mathrm{~h}$. Bound antibody on the membrane was detected using the SuperSignal West Dura Extended Duration Substrate (Pierce) according to the protocols supplied by the manufacturer. Quantification of bands was performed by using the NIH ImageJ software (available on the World Wide Web at rsb.info.nih.gov/nih-image) following a published method $[82,83]$.

\section{Measurement of proliferation with the MTT assay}

For proliferation assays, control or SMF-exposed hEBD LVEC cells were added to 96-well tissue culture plates at 3000 cells/well in serum-containing medium and cultured for up to nine days with the culture medium replenished every $3^{\text {rd }}$ day. To quantify cell proliferation by measuring metabolic activity, 3-(4,5-Dimethylthiazol-2yl)-2,5-diphenyltetrazolium bromide (MTT, (Sigma) was added to each well $(0.5 \mathrm{mg} / \mathrm{ml})$. After incubation for 3.0 $\mathrm{h}$ at $37^{\circ} \mathrm{C}$, the supernatants were aspirated, and $100 \mu \mathrm{l}$ of $n$-propyl alcohol containing $0.1 \%$ Nonidet P-40 and 4.0 $\mathrm{mM} \mathrm{HCl}$ were added. The colorimetric reaction was quantified by using an automatic plate reader, $\mu$ Quant (Bio-tek Instrument Inc., Winooski, VT) to measure absorbance at $570 \mathrm{~nm}$ with a reference filter of $690 \mathrm{~nm}$. Each MTT assay was carried out in triplicate. In all cases, measurement of proliferation through cell counting by using a Coulter Z2 instrument (as described in our previous publications [84]) yielded identical results.

\section{Detection of apoptosis by Annexin V/propidium iodide assays}

The Annexin V/propidium iodide flow cytometry method was used for the detection and quantification of apoptosis by following the procedure previously reported for Jurkat cells $[85,86]$ with the added step of trypsinizing the adherent hEBD LVEC cells (the previously-tested Jurkat cells grow in suspension and did not require this step). After trypsinization and resuspension in complete medium, cells were counted with a Coulter Z2 instrument, $1.0 \times 10^{6}$ cells from each sample were pelleted by centrifugation, washed by gentle resuspension in Dulbecco's phosphatebuffered saline, centrifuged again, and suspended in staining buffer. The cells were stained with fluorescein isothiocyanate-labeled Annexin V and propidium iodide and analyzed by flow cytometry as described previously $[85,86]$.

\section{Measurement of secreted IL-6 by ELISA}

Cells were seeded in triplicate in a 96 well culture plate at 6000 cells/well in $200 \mu \mathrm{l}$ of medium. After two days, cells were exposed to SMF and supernatant was collected over the time course indicated in the Results section and the concentration of IL- 6 was determined by an ELISA kit 
designed for this purpose (eBioscience, San Diego, CA) following the protocol provided by the manufacturer.

\section{Confocal imaging of Gal-C, GFAP, NEF and Vim}

hEBD LVEC cells $\left(1.0 \times 10^{5}\right.$ in $2.0 \mathrm{ml}$ of medium $)$ were plated on collagen coated $35 \mathrm{~mm}$ glass bottom dishes (35 mm, MatTek Corporation, Ashland, MA) and either exposed to SMF during culture or subject to normal cultivation. On day 4 the monolayers were fixed in reagent $A$ and permeabilized in reagent B (Fix \& Perm, Reagents A and B, Caltag Laboratories, Burlingame, CA) followed by washing with $3.0 \%$ BSA in PBS. Cells were incubated with anti-galactocerebroside (Gal-C, 1:100) (Sigma, Saint Louis, MO); anti-NEF 70 kD (1:100) (Chemicon, Temecula, CA); anti-GFAP (1:100) (Santa Cruz, Los Angeles, CA); or anti-vimentin (anti-Vim, 1:500) (BD Pharmingen, San Diego, CA) for $2.0 \mathrm{~h}$ at RT. The secondary antibody used to stain anti-GFAP, anti-NEF, and anti-Vim was Cy3conjugated Donkey anti-mouse $\operatorname{IgG}(\mathrm{H}+\mathrm{L})$ and $\mathrm{Cy3}-\mathrm{con}-$ jugated Donkey anti-Rabbit $\operatorname{IgG}(\mathrm{H}+\mathrm{L})$ was the secondary anti-body used for anti-Gal-C (both were obtained from Jackson ImmunoResearch Labs, West Grove, PA and used at a 1:100). In all cases, a solution of the high-affinity probe for F-actin Oregon Green ${ }^{\circledR} 488$ phalloidin (1:100) (Molecular Probes, now Invitrogen, Eugene, OR, Cat. No. O7466) was added to the monolayers and incubated for $20 \mathrm{~min}$ and the monolayers were stained with nuclearlocalizing dye DAPI $(1.0 \mu \mathrm{g} / \mathrm{mL})$ for $10 \mathrm{~min}$ at RT. The monolayers were then mounted using ProLong Gold ${ }^{\circledR}$ anti-fade reagent (Molecular Probes, Eugene, OR, Cat. No.P36934) and imaged by using a Zeiss 510 Meta confocal microscope.

\section{List of abbreviations}

GD3: ganglioside GM3 (Neu5Aco3Gal $\beta 4$ GlcCer); GM3: ganglioside GD3 (Neu5Aco8Neu5Aco3Gal $\beta 4$ GlcCer); hEBD LVEC: the human embryoid body derived LVEC cell line; IL-6: interleukin-6; LacCer: lactosylceramide (Galß4GlcCer); NEU3: neuramindase 3; qRT-PCR: quantitative real-time polymerase chain reaction; SD: standard deviation; SMF: static magnetic field(s); ST3GAL5: $\beta$ galactoside $\alpha$-2,3-sialyltransferase 5; TLR4: toll-like receptor 4 .

\section{Authors' contributions}

KJY was the principal investigator on this project, AS performed the microarray experiments and analysis, ZW designed, supervised, and carried out the majority of the cell, molecular, and biochemical assays performed in this study (P-LC provided substantial assistance in the design and execution of these experiments).

\section{Additional material}

\section{Additional file 1}

Annotation of the signaling networks identified to respond to SMF exposure in hEBD LVEC cells. The Ingenuity Pathway Analysis software tool was used to annotate the networks listed in Table 5 and the resulting diagrams are provided in Figures S1 through S9 (corresponding to ID\#19 , respectively).

Click here for file

[http://www.biomedcentral.com/content/supplementary/14712164-10-356-S1.ppt]

\section{Additional file 2}

Description of the SMF treatment device. The device used to treat cells with 0.23 to 0.28 T static magnetic fields is shown (in Figure S10) along with field orientation and strength.

Click here for file

[http://www.biomedcentral.com/content/supplementary/14712164-10-356-S2.ppt]

\section{Acknowledgements}

Funding for the bulk of this project was provided by Arnold and Mabel Beckman Foundation with the analysis of IL-6-mediated and gangliosideassociated responses funded the National Institutes of Health (NIBIB, grant 5RO IEB5692). The hEDB LVEC cell line was generously donated by Michael Shamblott (JHMI). We are grateful for technical assistance with the microarray experiments and pathway analysis from Conover Talbot (JHMI Microarray Core Facility), for helpful discussions with Wayne Bonlie, and for the gift of the magnetic treatment device from AMRI International (Calgary, $A B)$.

\section{References}

I. Wiltschko W, Wiltschko R: Magnetic orientation in birds. J Exp Biol 1996, 199:29-38.

2. Wiltschko W, Wiltschko R: Light-dependent magnetoreception in birds: the behaviour of European robins, Erithacus rubecula, under monochromatic light of various wavelengths and intensities. J Exp Biol 2001, 21 4:3295-3302.

3. Mora CV, Davison M, Wild JM, Walker MM: Magnetoreception and its trigeminal mediation in the homing pigeon. Nature 2004, 432:508-5II.

4. Presti D, Pettigrew JD: Ferromagnetic coupling to muscle receptors as a basis for geomagnetic field sensitivity in animals. Nature 1980, 285:99-101.

5. Maeda K, Henbest KB, Cintolesi F, Kuprov I, Rodgers CT, Liddell PA, Gust D, Timmel CR, Hore PJ: Chemical compass model of avian magnetoreception. Nature 2008, 453:387-390.

6. Cromie W]: Depressed get a lift from MRI. 2004 [http:// www.hno.harvard.edu/gazette/2004/0I.22/0I-depression.html]. Harvard University Gazette

7. Weintraub MI, Cole SP: A randomized controlled trial of the effects of a combination of static and dynamic magnetic fields on carpal tunnel syndrome. Pain Med 2008, 9:493-504.

8. Weintraub MI, Wolfe GI, Barohn RA, Cole SP, Parry G], Hayat G, Cohen JA, Page JC, Bromberg MB, Schwartz SL: Static magnetic field therapy for symptomatic diabetic neuropathy: a randomized, double-blind, placebo-controlled trial. Arch Phys Med Rehabil 2003, 84:736-746.

9. László J, Gyires K: 3 T homogeneous static magnetic field of a clinical MR significantly inhibits pain in mice. Life Sci 2009 , 84:12-17.

10. Okano $\mathrm{H}$, Ohkubo $\mathrm{C}$ : Modulatory effects of static magnetic fields on blood pressure in rabbits. Bioelectromagnetics 200I, 22:408-418 
II. Man D, Man B, Plosker H: The influence of permanent magnetic field therapy on wound healing in suction lipectomy patients: a double-blind study. Plast Reconstr Surg 1999, I 04:226 I-2266.

12. Weinberger A, Nyska A, Giler S: Treatment of experimental inflammatory synovitis with continuous magnetic field. Is J Med Sci 1996, 32:I I97-I20I.

13. Morris CE, Skalak TC: Chronic static magnetic field exposure alters microvessel enlargement resulting from surgical intervention. J Appl Physiol 2007, 1 03:629-636.

14. Nuccitelli S, Cerella C, Cordisco S, Albertini MC, Accorsi A, De Nicola M, D'Alessio M, Radogna F, Magrini A, Bergamaschi A, Ghibelli L: Hyperpolarization of plasma membrane of tumor cells sensitive to antiapoptotic effects of magnetic fields. Ann NY Acad Sci 2006, 1090:217-225.

15. De Nicola M. Cordisco S, Cerella C, Albertini MC, D'Alessio M, Accorsi A, Bergamaschi A, Magrini A, Ghibelli L: Magnetic fields protect from apoptosis via redox alteration. Ann NY Acad Sci 2006, I 090:59-68.

16. Rosen AD: Mechanism of action of moderate-intensity static magnetic fields on biological systems. Cell Biochem Biophys 2003, 39:163-173.

17. Rosen AD: Effect of $\mathbf{I} 25 \mathbf{~ m T}$ static magnetic field on the kinetics of voltage activated $\mathrm{Na}^{+}$channels in $\mathbf{G H} 3$ cells. Bioelectromagnetics 2003, 24:517-523.

18. Tenuzzo B, Chionna A, Panzarini E, Lanubile R, Tarantino P, Di Jeso $B$, Dwikat M, Dini L: Biological effects of $6 \mathrm{mT}$ static magnetic fields: A comparative study in different cell types. Bioelectromagnetics 2006, 27:560-577.

19. Szabo G, Dolganiuc A, Dai Q, Pruett SB: TLR4, ethanol, and lipid rafts: a new mechanism of ethanol action with implications for other receptor-mediated effects. I Immunol 2007 I 78: $1243-1249$

20. Chiu KH, Ou KL, Lee SY, Lin CT, Chang WJ, Chen CC, Huang HM: Static magnetic fields promote osteoblast-like cells differentiation via increasing the membrane rigidity. Ann Biomed Eng 2007, 35:1932-1939.

21. Mayburd AL, Martlínez A, Sackett D, Liu H, Shih J, Tauler J, Avis I, Mulshine JL: Ingenuity network-assisted transcription profiling: Identification of a new pharmacologic mechanism for MK886. Clin Cancer Res 2006, I 2: |820-1827.

22. Ganter B, Giroux CN: Emerging applications of network and pathway analysis in drug discovery and development. Curr Opin Drug Discov Devel 2008, I I :86-94.

23. Gusev Y: Computational methods for analysis of cellular functions and pathways collectively targeted by differentially expressed microRNA. Methods 2008, 44:6I-72.

24. Shamblott MJ, Axelman J, Littlefield JW, Blumenthal PD, Huggins GR, Cui Y, Cheng L, Gearhart JD: Human embryonic germ cell derivatives express a broad range of developmentally distinct markers and proliferate extensively in vitro. Proc Natl Acad Sci USA 2001, 98: I13-1।8.

25. Hirai T, Nakamichi N, Yoneda Y: Activator protein-I complex expressed by magnetism in cultured rat hippocampal neurons. Biochem Biophys Res Commun 2002, 292:200-207.

26. Huang $Y$, Yan J, Lubet R, Kensler TW, Sutter TR: Identification of novel transcriptional networks in response to treatment with the anticarcinogen 3H-I,2-dithiole-3-thione. Physiol Genomics 2006, 24: 144-153.

27. Petrov E, Martinac B: Modulation of channel activity and gadolinium block of MscL by static magnetic fields. Eur Biophys J 2007, 36:95-105

28. Jüttler E, Tarabin V, Schwaninger M: Interleukin-6 (IL-6): a possible neuromodulator induced by neuronal activity. Neuroscientist 2002, 8:268-275

29. Kühl M, Sheldahl LC, Park M, Miller JR, Moon RT: The Wnt/Ca ${ }^{2+}$ pathway: a new vertebrate Wnt signaling pathway takes shape. Trends Genet 2000, 16:279-283.

30. Strieth S, Strelczyk D, Eichhorn ME, Dellian M, Luedemann S, Griebel J, Bellemann M, Berghaus A, Brix G: Static magnetic fields induce blood flow decrease and platelet adherence in tumor microvessels. Cancer Biol Ther 2008, 7:814-819.

31. Okano H, Onmori R, Tomita N, lkada Y: Effects of a moderateintensity static magnetic field on VEGF-A stimulated endothelial capillary tubule formation in vitro. Bioelectromagnetics 2006, 27:628-640.
32. Okano H, Tomita N, lkada Y: Effects of I 20 mT static magnetic field on TGF- $\beta$ I-inhibited endothelial tubular formation in vitro. Bioelectromagnetics 2007, 28:497-499.

33. Okano H, Tomita N, Ikada Y: Spatial gradient effects of I $20 \mathbf{~ m T}$ static magnetic field on endothelial tubular formation in vitro. Bioelectromagnetics 2008, 29:233-236.

34. Lin CT, Lee SY, Chen CY, Chen CA, Lin CP, Huang HM: Long-term continuous exposure to static magnetic field reduces popolysaccharide-induced cytotoxicity of fibroblasts. Int J Radiat Biol 2008, 84:219-226.

35. Taga T, Fukuda S: Role of IL-6 in the neural stem cell differentiation. Clin Rev Allergy Immunol 2006, 28:249-256.

36. Dai JC, He P, Chen X, Greenfield EM: TNF $\alpha$ and PTH utilize distinct mechanisms to induce IL-6 and RANKL expression with markedly different kinetics. Bone 2006, 38:509-520.

37. Inoue KI, Takano H, Yanagisawa R, Sakurai M, Shimada A, Morita T, Sato M, Yoshino S, Yoshikawa T: Role of interleukin-6 in toll-like receptor 4 and 2 expressions induced by lipopolysaccharide in the lung. Immunopharmacol Immunotoxicol 2007, 29:63-68.

38. Jou I, Lee JH, Park SY, Yoon HJ, Joe E-H, Park EJ: Gangliosides trigger inflammatory responses via TLR4 in brain glia. Am J Patho 2006, 168:1619-1630

39. Song J, Duncan MJ, Li G, Chan C. Grady R, Stapleton A, Abraham SN A novel TLR4-mediated signaling pathway leading to IL-6 responses in human bladder epithelial cells. PLoS Pathogens 2007, 3:e60.

40. Triantafilou M, Morath S, Mackie A, Hartung T, Triantafilou K: Lateral diffusion of Toll-like receptors reveals that they are transiently confined within lipid rafts on the plasma membrane. J Cell Sci 2004, I 7:4007-40|4.

4I. Rehli M: Of mice and men: species variations of Toll-like receptor expression. Trends Immunol 2002, 23:375-378.

42. Weiss DS, Raupach B, Takeda K, Akira S, Zychlinsky A: Toll-like receptors are temporally involved in host defense. I Immunol 2004, I 72:4463-4469.

43. Muzio M, Bosisio D, Polentarutti N, D'amico G, Stoppacciaro A, Mancinelli R, van't Veer C, Penton-Rol G, Ruco LP, Allavena P, Mantovani A: Differential expression and regulation of toll-like receptors (TLR) in human leukocytes: selective expression of TLR3 in dendritic cells. J Immunol 2000, I 64:5998-6004.

44. Rosen $A D$, Chastney EE: Effect of long term exposure to $\mathbf{0 . 5} \mathbf{T}$ static magnetic fields on growth and size of $\mathbf{G H} 3$ cells. Bioelectromagnetics 2009, 30: I |4- I I9.

45. Tenuzzo B, Vergallo C, Dini L: Effect of $6 \mathbf{m T}$ static magnetic field on the bcl-2, bax, p53 and hsp70 expression in freshly isolated and in vitro aged human lymphocytes. Tissue Cell 2009, 4 I: I69-179.

46. Fedrowitz $M$, Kamino K, Löscher W: Significant differences in the effects of magnetic field exposure on 7,12- dimethylbenz $(\alpha)$ anthracene-induced mammary carcinogenesis in two substrains of Sprague-Dawley rats. Cancer Res 2004, 64:243-25I.

47. Ueno S, Saito S, Wada T, Yamaguchi K, Satoh M, Arai Y, Miyagi T: Plasma membrane-associated sialidase is up-regulated in renal cell carcinoma and promotes interleukin-6-induced apoptosis suppression and cell motility. I Biol Chem 2006, 28I:7756-7764

48. Hakomori S-I: The glycosynapse. Proc Natl Acad Sci USA 2002 , 99:225-232.

49. Allende ML, Proia RL: Lubricating cell signaling pathways with gangliosides. Curr Opin Struct Biol 2002, I 2:587-592.

50. Van Wagoner NJ, Benveniste EN: Interleukin-6 expression and regulation in astrocytes. J Neuroimmunol 1999, I 00: I24-I39.

51. Chung T-W, Choi H-J, Lee Y-C, Kim C-H: Molecular mechanism for transcriptional activation of ganglioside $\mathrm{GM} 3$ synthase and its function in differentiation of HL-60 cells. Glycobiology 2005, 15:233-244.

52. Kamimura D, Ishihara $\mathrm{K}$, Hirano $\mathrm{T}$ : IL-6 signal transduction and its physiological roles: the signal orchestration model. $\operatorname{Rev}$ Physiol Biochem Pharmacol 2003, I49: I-38.

53. Odintsova E, Butters TD, Monti E, Sprong H, van Meer G, Berditchevski F: Gangliosides play an important role in the organization of CD82-enriched microdomains. Biochem J 2006, 400:315-325 
54. Müthing J, Maurer U, Weber-Schürholz S: Glycosphingolipids of skeletal muscle: II. Modulation of $\mathrm{Ca}^{2+}$-flux in triad membranes by gangliosides. Carbohydr Res 1998, 307:147-157.

55. Zhang X, Min X, Yang F: Conformational basis of the phospholipid requirement for the activity of SR $\mathrm{Ca}^{2+}$-ATPase. Chem Phys Lipids 1998, 97:55-64.

56. Wang Y, Tsui Z, Yang F: Mechanistic study of modulation of SR $\mathrm{Ca}^{2+}$-ATPase activity by gangliosides GMI and GM3 through some biophysical measurements. Glycoconjug J 1999 , 16:781-786

57. Wang LH, Tu YP, Yang XY, Tsui ZC, Yang FY: Effect of ganglioside GM3 on the activity and conformation of reconstituted $\mathrm{Ca}^{2+}$ ATPase. FEBS Lett 1996, 388:128-130.

58. Wang Y, Tsui Z, Yang F: Antagonistic effect of ganglioside GMI and $G M 3$ on the activity and conformation of sarcoplasmic reticulum $\mathrm{Ca}^{2+}$-ATPase. FEBS Lett 1999, 457:|44-I48.

59. Nakashima K, Takizawa T, Ochiai W, Yanagisawa M, Hisatsune T, Nakafuku M, Miyazono K, Kishimoto T, Kageyama R, Taga T: BMP2 mediated alteration in the developmental pathway of fetal mouse brain cells from neurogenesis to astrocytogenesis. Proc Natl Acad Sci USA 200I, 98:5868-5873.

60. See J, Zhang X, Eraydin N, Mun S-B, Mamontov P, Golden JA, Grinspan JB: Oligodendrocyte maturation is inhibited by bone morphogenetic protein. Mol Cell Neurosci 2004, 26:48I-492.

61. Zhang P-L, Izrael M, Ainbinder E, Ben-Simchon L, Chebath J, Revel M: Increased myelinating capacity of embryonic stem cell derived oligodendrocyte precursors after treatment by interleukin-6/soluble interleukin-6 receptor fusion protein. Mol Cell Neurosci 2006, 3 I:387-398.

62. Henderson B, Kind M, Boeck G, Helmberg A, Wick G: Gene expression profiling of human endothelial cells exposed to $50-\mathrm{Hz}$ magnetic fields fails to produce regulated candidate genes. Cell Stress Chaperones 2006, I I:227-232.

63. Blank M, Goodman R: Electromagnetic initiation of transcription at specific DNA sites. J Cell Biochem 200I, 8I:689-692.

64. Lin H, Han L, Blank M, Head M, Goodman R: Magnetic field activation of protein-DNA binding. / Cell Biochem 1998, 70:297-303.

65. Lin $H$, Blank $M$, Goodman $R$ : A magnetic field-responsive domain in the human HSP70 promoter. J Cell Biochem 1999 , 75: $170-176$

66. Lin H, Blank M, Rossol-Haseroth K, Goodman R: Regulating genes with electromagnetic response elements. I Cell Biochem 200I, 8I: | $43-148$

67. Eichwald C, Walleczek J: Magnetic field perturbations as a tool for controlling enzyme-regulated and oscillatory biochemical reactions. Biophys Chem 1998, 74:209-224.

68. Henbest KB, Maeda K, Hore PJ, Joshi M, Bacher A, Bittl R, Weber S, Timmel CR, Schleicher E: Magnetic-field effect on the photoactivation reaction of Escherichia coli DNA photolyase. Proc Natl Acad Sci USA 2008, 105: I 4395-14399.

69. Rodgers CT, Hore PJ: Chemical magnetoreception in birds: the radical pair mechanism. Proc Natl Acad Sci USA 2009, 106:353-360.

70. Gray JR, Frith $\mathrm{CH}$, Parker D: In vivo enhancement of chemotherapy with static electric or magnetic fields. Bioelectromagnetics 2000, 21:575-583.

7I. Tofani S, Barone D, Cintorino M, de Santi MM, Ferrara A, Orlassino R, Ossola P, Peroglio F, Rolfo K, Ronchetto F: Static and ELF magnetic fields induce tumor growth inhibition and apoptosis. Bioelectromagnetics 2001, 22:419-428.

72. Campbell CT, Aich U, Weier CA, Wang JJ, Choi SS, Wen MM, Maisel K, Sampathkumar S-G, Yarema KJ: Targeting pro-invasive oncogenes with short chain fatty acid-hexosamine analogs inhibits the mobility of metastatic MDA-MB-23 I breast cancer cell. J Med Chem 2008, 5 I:8I35-8I47.

73. Bonlie DR: Treatment using oriented unidirectional DC magnetic field. United States Patent 200I.

74. Engström S, Markov MS, McLean MJ, Holcomb RR, Markov JM: Effects of non-uniform static magnetic fields on the rate of myosin phosphorylation. Bioelectromagnetics 2002, 23:475-479.

75. Edgar R, Domrachev M, Lasha AE: Gene Expression Omnibus: NCBI gene expression and hybridization array data repository. Nucleic Acids Res 2002, 30:207-2I0.

76. Kirschbaum B: Effect of high bicarbonate hemodialysis on ionized calcium and risk of metastatic calcification. Clin Chim Acta 2004, 343:231-236.
77. Wang Z, Sun Z, Li AV, Yarema KJ: Roles for GNE outside of sialic acid biosynthesis: modulation of sialyltransferase and BiP expression, GM3 and GD3 biosynthesis, proliferation and apoptosis, and ERKI/2 phosphorylation. J Biol Chem 2006, 28 I:27016-27028.

78. Elmouelhi N, Aich U, Paruchuri VD, Meledeo MA, Campbell CT, Wang JJ, Srinivas R, Khanna HS, Yarema KJ: Hexosamine template. A platform for modulating gene expression and for sugar-based drug discovery. J Med Chem 2009, 52:25I5-2530.

79. Livak KJ, Schmittgen TD: Analysis of relative gene expression data using real-time quantitative PCR and the $2^{-\Delta \Delta C T}$ method. Methods 200I, 25:402-408.

80. Lovat PE, Di Sano F, Corazzari M, Fazi B, Donnorso RP, Pearson AD, Hall AG, Redfern CP, Piacentini M: Gangliosides link the acidic sphingomyelinase-mediated induction of ceramide to 12 lipoxygenase-dependent apoptosis of neuroblastoma in response to fenretinide. J Nat/ Cancer Inst 2004, 96: I 288-I 299.

8I. Siddiqui RA, Jenski LJ, Harvey KA, Wiesehan JD, Stillwell W, Zaloga GP: Cell-cycle arrest in Jurkat leukaemic cells: a possible role for docosahexaenoic acid. Biochem / 2003, 37 I:62 I-629.

82. Cen S, Guo F, Niu M, Saadatmand J, Deflassieux J, Kleiman L: The interaction between HIV-I Gag and APOBEC3G. J Biol Chem 2004, 279:33|77-33/84.

83. Sampathkumar S-G, Jones MB, Meledeo MA, Campbell CT, Choi SS, Hida K, Gomutputra P, Sheh A, Gilmartin T, Head SR, Yarema KJ: Targeting glycosylation pathways and the cell cycle: sugardependent activity of butyrate-carbohydrate cancer prodrugs. Chem Biol 2006, I 3:1265-1275.

84. Jones MB, Teng H, Rhee JK, Baskaran G, Lahar N, Yarema KJ: Characterization of the cellular uptake and metabolic conversion of acetylated $\mathbf{N}$-acetylmannosamine (ManNAc) analogues to sialic acids. Biotechnol Bioeng 2004, 85:394-405.

85. Kim EJ, Jones MB, Rhee JK, Sampathkumar SG, Yarema KJ: Establishment of $\mathbf{N}$-acetylmannosamine (ManNAc) analogue-resistant cell lines as improved hosts for sialic acid engineering applications. Biotechnol Prog 2004, 20:1674-1682.

86. Kim EJ, Sampathkumar SG, Jones MB, Rhee JK, Baskaran G, Yarema $\mathrm{KJ}$ : Characterization of the metabolic flux and apoptotic effects of O-hydroxyl- and N-acetylmannosamine (ManNAc) analogs in Jurkat (human T-lymphoma-derived) cells. J Biol Chem 2004, 279: 18342-18352.

Publish with Biomed Central and every scientist can read your work free of charge

"BioMed Central will be the most significant development for disseminating the results of biomedical research in our lifetime. "

Sir Paul Nurse, Cancer Research UK

Your research papers will be:

- available free of charge to the entire biomedical community

- peer reviewed and published immediately upon acceptance

- cited in PubMed and archived on PubMed Central

- yours - you keep the copyright 